\title{
LEÑOS FÓSILES DE LA FORMACIÓN EL PALMAR (PLEISTOCENO TARDÍO) EN EL PARQUE NACIONAL EL PALMAR, ENTRE RÍOS, ARGENTINA
}

\author{
R. SOLEDAD RAMOS ${ }^{1,3}$, MARIANA BREA $^{1,4}$ Y DANIELA M. KRÖHLING $^{2,4}$ \\ ${ }^{1}$ Centro de Investigaciones Científicas y Transferencia de Tecnología a la Producción (CICyTTP-CONICET), Dr. Matteri y España SN, E3105BWA Diamante, Entre \\ Ríos, Argentina.laresole@hotmail.com,cidmbrea@infoaire.com.ar \\ ${ }^{2}$ Facultad de Ingeniería y Ciencias Hídricas, Universidad Nacional del Litoral, CC 217, 3000 Santa Fe, Argentina.dkrohling@santafe-conicet.gov.ar \\ ${ }^{3}$ FONCyT- Agencia Nacional de Promoción Científica y Tecnológica \\ ${ }^{4}$ CONICET- Consejo Nacional de Investigaciones Científicas y Técnicas
}

\begin{abstract}
Resumen. Este trabajo analiza nuevos leños fósiles de la Formación El Palmar (Pleistoceno tardío) que fueron recuperados en el Parque Nacional El Palmar, centro-este de la provincia de Entre Ríos, Argentina. Se describen dos nuevas especies, una de Beilschmiedioxylon DupéronLaudoueneix y Dupéron 2005 (Lauraceae) y otra de Terminalioxylon Schönfeld 1947 (Combretaceae) así como también se cita por primera vez en depósitos pleistocénicos de Argentina a Piptadenioxylon chimeloi Suguio y Mussa 1978 (Fabaceae-Mimosoideae) descripto para los depósitos aluviales antiguos del río Tietê "Porto de areia de Itaquaquecetuba", San Pablo, Brasil. Los caracteres anatómicos de los leños fósiles sugieren una afinidad con los taxones actuales Beilschmiedia taubertiana (Schw. y Mez) Kosterm., Terminalia australis Cambess y Parapiptadenia Brenan respectivamente. Las características ecológicas y distribución de los parientes actuales más cercanos se utilizaron para realizar inferencias paleogeográficas, paleoclimáticas y paleoecológicas. Estos registros fósiles permiten inferir para el centro-este de Entre Ríos y durante el período en el cual se desarrolló dicha formación geológica, condiciones climáticas cálidas y húmedas. Los leños fósiles corresponderían a componentes de bosques mixtos ribereños (Lauraceae y Combretaceae) y bosques mixtos semiáridos (Fabaceae).
\end{abstract}

Palabras clave. Leños fósiles. Formación El Palmar. Pleistoceno tardío. Lauraceae. Combretaceae. Fabaceae. Argentina.

Abstract. FOSSIL WOOD FROM EL PALMAR FORMATION (LATE PLEISTOCENE) IN THE EL PALMAR NATIONAL PARK, ENTRE RÍOS, ARGENTINA. This paper analyzes new fossil wood from El Palmar Formation (late Pleistocene) recovered from the El Palmar National Park, central-eastern Entre Ríos province, Argentina. Two new morphospecies of Beilschmiedioxylon Dupéron-Laudoueneix and Dupéron 2005 (Lauraceae) and other of Terminalioxylon Schönfeld 1947 (Combretaceae) are described, as well as Piptadenioxylon chimeloi Suguio and Mussa 1978 (Fabaceae-Mimosoideae) is cited for the first time in Pleistocene deposits of Argentina. This species was described from the ancient alluvial Tietê River "Porto de areia of Itaquaquecetuba", São Paulo, Brazil. Wood anatomical characters suggest an affinity with the taxa Beilschmiedia taubertiana (Schw. and Mez) Kosterm., Terminalia australis Cambess, and Parapiptadenia Brenan respectively. The relationships and comparisons with the nearest living relatives were used to infer paleogeographic, paleoclimatic and paleoecological requirements. This fossil record suggests warm and humid climatic conditions for central-eastern of Entre Ríos, and during the period comprising the development of this geological formation. The fossil wood would correspond to components of riparian mixed forests (Lauraceae and Combretaceae) and semi-arid mixed forests (Fabaceae).

Key words. Fossil woods. El Palmar Formation. Late Pleistocene. Lauraceae. Combretaceae. Fabaceae. Argentina.

EL registro paleobotánico de la Formación El Palmar es muy abundante en leños fósiles y en asociaciones fitolíticas. La paleoflora está caracterizada por elementos arbóreos, arbustivos y herbáceos pertenecientes a las familias Lauraceae, Combretaceae, Myrtaceae, Fabaceae, Anacardiaceae, Arecaceae, Podostemaceae, Poaceae y Cyperaceae (Zucol et al., 2005; Brea y Zucol, 2011 y referencias allí citadas; Patterer y Brea, 2011).

La Formación El Palmar (definida por Iriondo en 1980) es una importante faja de acumulación fluvial vinculada al río Uruguay, desde los c. $29^{\circ} \mathrm{S}$ a $33^{\circ} \mathrm{S}$. Según Iriondo y Kröhling (2007) y Kröhling (2009), está representada por una llanura aluvial abandonada, compuesta por depósitos de canal de alta energía y sedimentos asociados de inundación y constituye la terraza alta del río Uruguay a lo largo de $c$. 1000 km, desde Chapecó en Brasil (27º $)$ hasta Concepción del Uruguay en la frontera Argentina-Uruguay (32³0'S). La terraza es discontinua en la alta cuenca del río Uruguay, pero alcanza buen desarrollo y continuidad en la cuenca media, que abarca el este de la provincia de Entre Ríos en Argentina y el Oeste de la República Oriental del Uruguay. En este último territorio, dicha unidad se conoce como Formación Salto (Bossi, 1969; Iriondo, 1980; Veroslavsky y Montaño, 2004; Iriondo y Kröhling, 2007; Kröhling, 2009). Dataciones por termoluminiscencia indican edades entre 80 y $88 \mathrm{ka}$ AP para 
la parte superior aflorante (representada por arenas de cauce) de la Formación El Palmar (Iriondo y Kröhling, 2008 y referencias allí citadas). De acuerdo con las características sedimentológicas, estratigráficas y estas primeras dataciones de la unidad, Kröhling (2009) interpreta que la misma se habría generado durante el Estadio Isotópico Marino del Oxígeno EIO 5a, correspondiente a uno de los interestadiales cálidos a nivel global del Cuaternario superior.

En esta contribución se describen nuevos leños fósiles asignados a las familias Combretaceae, Lauraceae y Fabaceae que fueron hallados en los depósitos sedimentarios que afloran en el Parque Nacional El Palmar, en la localidad fosilífera El Palmar 1-99 (31 $54^{\circ}$ S- $58^{\circ} 14^{\prime} \mathrm{O}$ ) en el NF2 (ver mapa de ubicación en Zucol et al., 2005). Dicho parque está ubicado en el área tipo de la Formación El Palmar en el este de Entre Ríos, un área representada por una faja fluvial de 4 a $15 \mathrm{~km}$ de ancho a lo largo de la margen derecha del río Uruguay, cuya expresión morfológica corresponde al de la terraza alta del río Uruguay (Iriondo, 1980; Iriondo y Kröhling, 2001, 2007, 2008).

Las implicancias paleogeográficas y paleoecológicas de la distribución de dichos taxones fósiles fueron analizadas teniendo en cuenta las características ecológicas y de distribución de los parientes actuales más cercanos.

\section{MARCO GEOLÓGICO Y PALEONTOLÓGICO}

Los leños fósiles fueron hallados en el Parque Nacional El Palmar $\left(31^{\circ} 25^{\prime} \mathrm{S}-58^{\circ} 02^{\prime} \mathrm{O}\right)$, situado entre las ciudades de Colón y Nueva Escocia, provincia de Entre Ríos (ver mapa de ubicación en Zucol et al., 2005). Iriondo (1980) definió el perfil tipo de esta unidad en dicho parque, a partir de varias perforaciones de estudio localizadas a $1 \mathrm{~km}$ al sur del arroyo El Palmar y del levantamiento de perfiles aflorantes del área.

De acuerdo con Iriondo y Kröhling (2008) y Kröhling (2009), la Formación El Palmar en su área tipo está constituida por arenas cuarzosas amarillentas a rojizas con un espesor aflorante que varía entre 3 y $12 \mathrm{~m}$; contiene estratos lenticulares de cantos rodados y gravas de composición principalmente silícea, de decenas de metros de largo. Las lentes formadas por cantos rodados, resultando más resistentes a la erosión, forman los sectores remanentes de la terraza en áreas muy disectadas, recibiendo el nombre local de "cerros". En muchos lugares, el sedimento contiene proporciones significativas de fracciones finas (limo-arcilla) y cemento férrico que le otorga un color general ocre-rojizo a la unidad. La formación está poco consolidada y con variable grado de cementación ante diferente grado de humedad presente en el sedimento. La unidad apoya en discordancia erosiva sobre basalto cretácico (Formación Serra Geral) o areniscas cretácicas (Formación Puerto Yeruá). Está cubierta localmente por sedimentos eólicos del Holoceno tardío o por un depósito residual moderno. Los materiales que componen la unidad en análisis derivan de areniscas cuarzosas y basaltos mesozoicos de la alta cuenca del Uruguay.

El perfil estratigráfico integrado aflorante en una cantera abandonada donde fue recuperado el material fósil se presenta en la Figura 1. La secuencia sedimentaria aflora con $c$. $3 \mathrm{~m}$ de espesor y está compuesta principalmente por arenas medias cuarzosas, de color rojizo y amarillento y con estratificación planar difusa, incluyendo lentes de cantos rodados finos a medianos y gravas, de composición dominantemente silícea (con alto grado de redondeamiento y mediana esfericidad) y con escasa matriz arenosa. En los estratos arenosos fueron hallados los leños fósiles. Los estratos gravosos lateralmente pasan a estratos de arenas medias a gruesas con estratificación cruzada planar. Las características del depósito señalan la existencia de facies de canal de alta energía

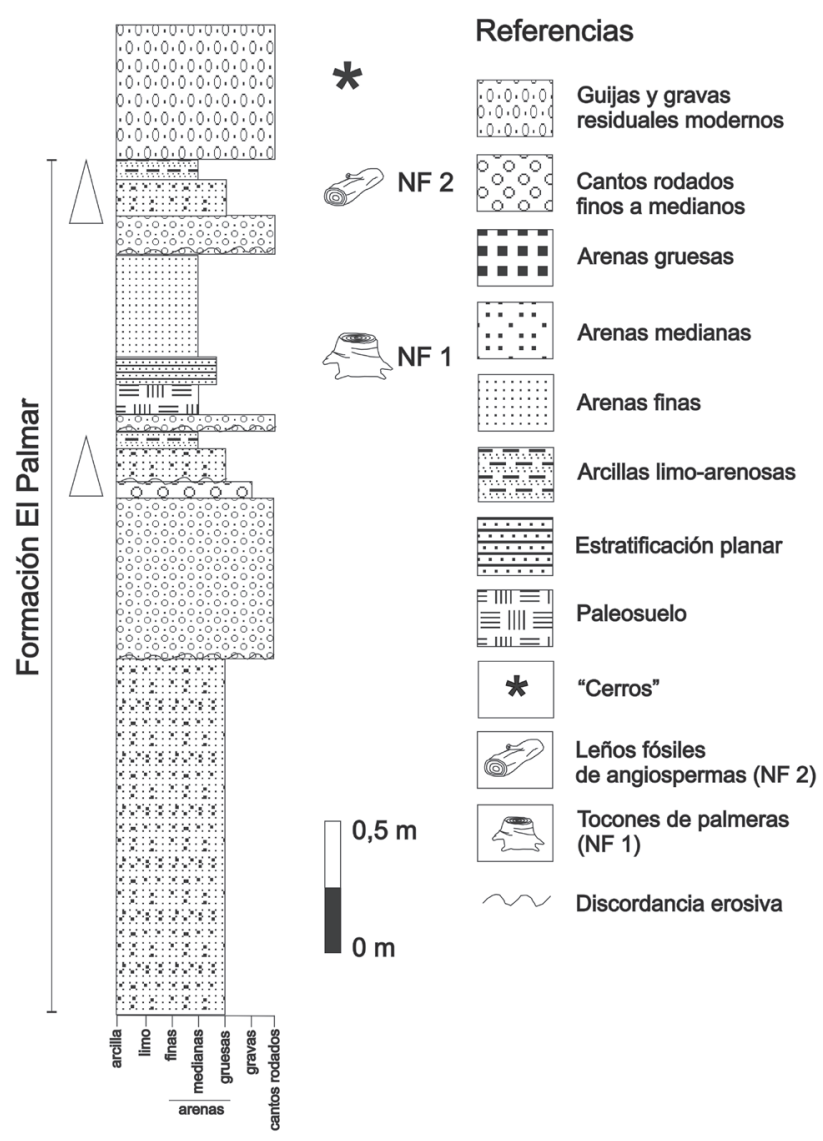

Figura 1. Sección esquemática de la Formación El Palmar en el Parque Nacional El Palmar/ Schematic section of the El Palmar Formation in El Palmar National Park. 
y de elevada turbulencia, evidenciado por la baja selección, la escasa matriz presente y la existencia de estructuras sedimentarias de fondo plano de alto régimen, especialmente en los estratos gravosos (Iriondo y Kröhling, 2008). El primer registro fósil de vertebrados para la Formación El Palmar hallado en las cercanías de la ciudad de Colón (Entre Ríos) fue Stegomastodon platensis Ameghino, 1888, un fósil característico de la Edad Mamífero Sudamericana (South American Land Mammal Ages, SALMA's) Lujanense (Tonni, 1987). Recientemente Ferrero et al. (2007) y Brandoni et al. (2010), identificaron 8 nuevos géneros hallados en la localidad fosilífera El Boyero (Concordia, Entre Ríos) donde corroboraron la edad Lujanense (Pleistoceno tardío-Holoceno temprano) para esta asociación de vertebrados.

Los registros paleobotánicos preservados como leños permineralizados y fitolitos en la Formación El Palmar son abundantes. Los leños fósiles registrados hasta la actualidad son: Laurinoxylon mucilaginosum (Brea) Dupéron-Laudoueneix y Dupéron 2005, L. artabeae (Brea) Dupéron-Laudoueneix y Dupéron 2005, Terminalioxylon concordiensis Brea y Zucol 2001, Eugenia sp. (Brea et al., 2001), Menendoxylon mesopotamiensis Lutz 1979, M. areniensis Lutz 1979, M. piptadiensis Lutz 1987, Mimosoxylon caccavariae Brea, Zucol y Patterer 2010, Prosopisinoxylon castroae Brea, Zucol y Patterer 2010, Holocalyxylon cazzoi Brea, Zucol y Patterer 2010, Amburanoxylon tortorellii Brea, Zucol y Patterer 2010, Schinopsixylon heckii Lutz 1979, Palmoxylon concordiensis Lutz 1980 y P. yuqueriensis Lutz 1984 (Brea y Zucol, 2011 y referencias allí citadas).

Zucol et al. (2005) dieron a conocer una asociación fitolítica en la misma localidad fosilífera que el material estudiado en este trabajo. La asociación está integrada por Poaceae del tipo panicoide, Cyperaceae, Podostemaceae, Arecaceae y angiospermas indeterminadas; asociadas con espículas de esponjas de agua dulce. Las stegmatas de Arecaceae confirman la presencia en áreas próximas de comunidades de palmeras afines a Butia yatay (Mart.) Becc. Se encuentra bajo análisis el estudio comparativo de las asociaciones fitolíticas y sus desgastes superficiales en las diferentes facies sedimentarias de la Formación El Palmar con la finalidad de poder establecer autoctonías/aloctonías de las mismas (Patterer y Brea, 2011); esta tarea forma parte la Tesis Doctoral de N. Patterer.

\section{MATERIALES Y MÉTODOS}

Los leños fósiles de origen alóctono a parautóctono estudiados en este trabajo fueron hallados en los niveles superiores de la Formación El Palmar en el nivel fosilífero NF2 (Fig. 1), mientras que los estípites "in situ” provenientes del NF1 y algunos leños de angiospermas hallados en el NF2 fueron estudiados previamente por Zucol et al. (2005). El levantamiento del perfil estratigráfico integrado se realizó aplicando los principios y técnicas clásicas de la estratigrafía física y la sedimentología.

Los leños están permineralizados por sílice. Se realizaron secciones delgadas de los tres cortes característicos (corte transversal, longitudinal tangencial y longitudinal radial). La terminología para las descripciones anatómicas fue tomada del listado del IAWA Committee (1989). Se utilizaron algunos términos y clasificaciones de Carlquist (2001), Kribs (1935), Chattaway (1932) y las recopilaciones bibliográficas de Gregory (1994) y Gregory et al. (2009).

Para la identificación de los leños fósiles se utilizaron los atlas y descripciones de Metcalfe y Chalk (1950a, 1950b), Cozzo (1951), Tortorelli (1956), Evans et al. (2006) y la base de datos del InsideWood (InsideWood, 2004).

Se siguió la clasificación sistemática del APG III (2009). Se utilizaron el International Plant Names Index (The Plant List, 2010) y el Index Nominum Genericorum (ING) (Farr y Zijlstra, 1996) para los nombres de las especies actuales y fósiles.

Los valores cuantitativos de las descripciones anatómicas constituyen promedios de 25 medidas, en todos los casos se cita primero la media y entre paréntesis las medidas mínimas y máximas del rango de distribución. El material fue estudiado con un microscopio Nikon Eclipse E200 y las microfotografías fueron tomadas con una cámara digital Nikon Coolpix S4. Los ejemplares se encuentran depositados en la Colección Paleobotánica del Laboratorio de Paleobotánica, CICyTTP-CONICET Diamante, bajo el acrónimo CIDPALBO y CID-PALBO mic.

\section{PALEONTOLOGÍA SISTEMÁTICA}

Clase Magnoliopsida Brongniart 1843

Subclase Magnolimdae Takhtajan 1967

Orden Laurales Berchtold y Presley 1820

Familia Lauraceae de Jussieu 1789

Género Beilschmiedioxylon Dupéron-Laudoueneix y Dupéron 2005

Especie tipo. Beilschmiedioxylon africanum Dupéron-Laudoueneix y Dupéron 2005

\section{Beilschmiedioxylon parataubertiana sp. nov.} Figura 2.1-13

Derivación del nombre. El epíteto específico, parataubertia$n a$, indica su estrecha afinidad con Beilschmiedia taubertiana (Schw. y Mez) Kosterm. 
Diagnosis. Porosidad difusa; los vasos son principalmente solitarios y múltiples radiales de 3-5 y agrupados; elementos de vaso medianos a grandes, moderadamente numerosos $\left(<20\right.$ por $\left.\mathrm{mm}^{2}\right)$; placa de perforación simple; puntuaciones intervasculares pequeñas, areoladas, alternas, ovales y ornadas; tilosis abundante; radios heterocelulares compuestos por células procumbentes, verticales y cúbicas; principalmente multiseriados de 4 células de ancho y raros de 2-3 seriados y uniseriados; moderadamente anchos, muy bajos a bajos; células agregadas presentes; parénquima axial vasicéntrico escaso a raro; fibras de paredes delgadas a gruesas; septadas y no septadas; células oleíferas en radios y parénquima axial; cristales romboidales en células de radios y en lumen de los vasos.

Diagnosis. Diffuse-porous; vessels mostly solitary, radial multiples of 3-5 and clusters; medium and large vessels, moderately numerous ( $<20$ per $\left.\mathrm{mm}^{2}\right)$; perforation plate simple; intervessel pits small, bordered, alternate, oval and vestured; abundant tylosis; rays heterocellular and composed of procumbent, upright and square cells; mainly multiseriate rays 4 cells wide and rare 2-3 seriate and uniseriate; moderately wide and very low and low; cell aggregates are present; axial parenchyma vasicentric scarce to rare; fibres thin- to thick-walled, septate and nonseptate; "oil cells" in rays and axial parenchyma; rhomboidal crystals in rays cells and vessel lumen.

Material tipo. CID-PALBO 9, CID-PALBO mic. 163 (tres preparados microscópicos).

Procedencia geográfica. Parque Nacional El Palmar, Entre Ríos, Argentina.

Procedencia estratigráfica. Formación El Palmar (Pleistoceno tardío).

Descripción. En corte transversal, los anillos de crecimiento son indistinguibles. La porosidad es difusa. Los vasos son solitarios (50\%), múltiples radiales de 3 a 5 elementos (40\%) y agrupados (10\%) (Fig. 2.1). El diámetro tangencial promedio es de 126 (69-233) $\mu \mathrm{m}$ y el diámetro radial promedio es de $123(66-225) \mu \mathrm{m}$. Las paredes de los elementos vasales tienen un espesor de $10(5-15) \mu \mathrm{m}$. La densidad es de $14(13-18)$ por $\mathrm{mm}^{2}$. Los vasos presentan abundante tilosis (Fig. 2.8, 13) y tilosis en formación (Fig. 2.3). El parénquima axial es paratraqueal vasicéntrico escaso a raro (Fig. 2.1). Las fibras se disponen en hileras radiales (6-22 hileras entre dos radios consecutivos), son de contorno hexagonal, oval y/o circular (Fig. 2.4), con un diámetro promedio de 20 $(15-29) \mu \mathrm{m}$ y sus paredes son finas a gruesas con un espesor de pared de 5 (3-6) $\mu \mathrm{m}$.

En corte longitudinal tangencial, los elementos de va- sos tienen una longitud promedio de 346 (196-720) $\mu \mathrm{m}$. Presentan tabiques horizontales a levemente oblicuos y las placas de perforación son simples (Fig. 2.2, 3). Las puntuaciones intervasculares son alternas (Fig. 2.3, 6), ornadas, ovales y pequeñas con un diámetro de 4 a $7 \mu \mathrm{m}$. Los radios son predominantemente 4 seriados (90\%), muy escasos 2-3 seriados (5\%) y uniseriados (5\%) (Fig. 2.3, 5, 7). Los radios son heterogéneos del tipo II de Kribs y son comunes las células agregadas. Los radios multiseriados tienen una altura promedio de 572 (294-1000) $\mu \mathrm{m}$ y expresada en número de células es de 29 (11-45), los radios uniseriados tienen una altura de 120 (80-150) $\mu \mathrm{m}$ y expresada en número de células de 8 (3-11) células. El ancho de los radios multiseriados es de $60(35-100) \mu \mathrm{m}$ y de los uniseriados es de 35 (25-50) $\mu \mathrm{m}$. Son moderadamente numerosos con 8 (7-10) radios por mm lineal. Los radios presentan en sus extremos idioblastos con contenidos probablemente oleíferoso mucilaginosos (Fig. 2.7, 11). Las células oleíferas también están presentes en el parénquima axial (Fig. 2.1, 8, 9). Las fibras son septadas y no septadas. Se observan cristales romboidales pequeños $(15-25 \mu \mathrm{m})$ presentes en las células verticales de los radios, uno por célula (Fig. 2.2). Los cristales ubicados en el lumen de los elementos vasales son numerosos (Fig. 2.10). Tanto los radios como las fibras presentan depósitos sólidos oscuros a rojizos-marrones (Fig. 2.1, 8, 9).

En corte longitudinal radial, los radios son heterocelulares compuestos por células procumbentes formando el cuerpo de los radios y células verticales o cúbicas en los extremos (Fig. 2.12).

Comparación con especies actuales. Las características anatómicas del ejemplar fósil restringen las comparaciones a las Lauraceae, las cuales se distinguen por presentar porosidad difusa, vasos solitarios, múltiples radiales y agrupados; puntuaciones intervasculares alternas; radios predominantemente de 2-4 células de ancho y ocasionalmente uniseriados; homocelulares o heterocelulares; fibras ocasionalmente septadas; parénquima axial vasicéntrico y presencia de células oleíferas o mucilaginosas (Patel, 1987; Richter, 1987; Wheeler et al., 1987; León, 2000; León y Espinosa de Pernía, 2000; Parra, 2009).

A pesar de que las Lauraceae poseen leño anatómicamente homogéneos (Richter, 1987; Callado y Costa, 1997) y los géneros dentro de la familia se diferencian por sus órganos reproductores y vegetativos, se encontró una gran afinidad con Aniba Aublet, Cryptocarya R. Brown y Beilschmiedia C.G.D Ness, siendo con este último más estrecha las semejanzas. Beilschmiedioxylon parataubertiana sp. nov. se asemeja a Beils- 

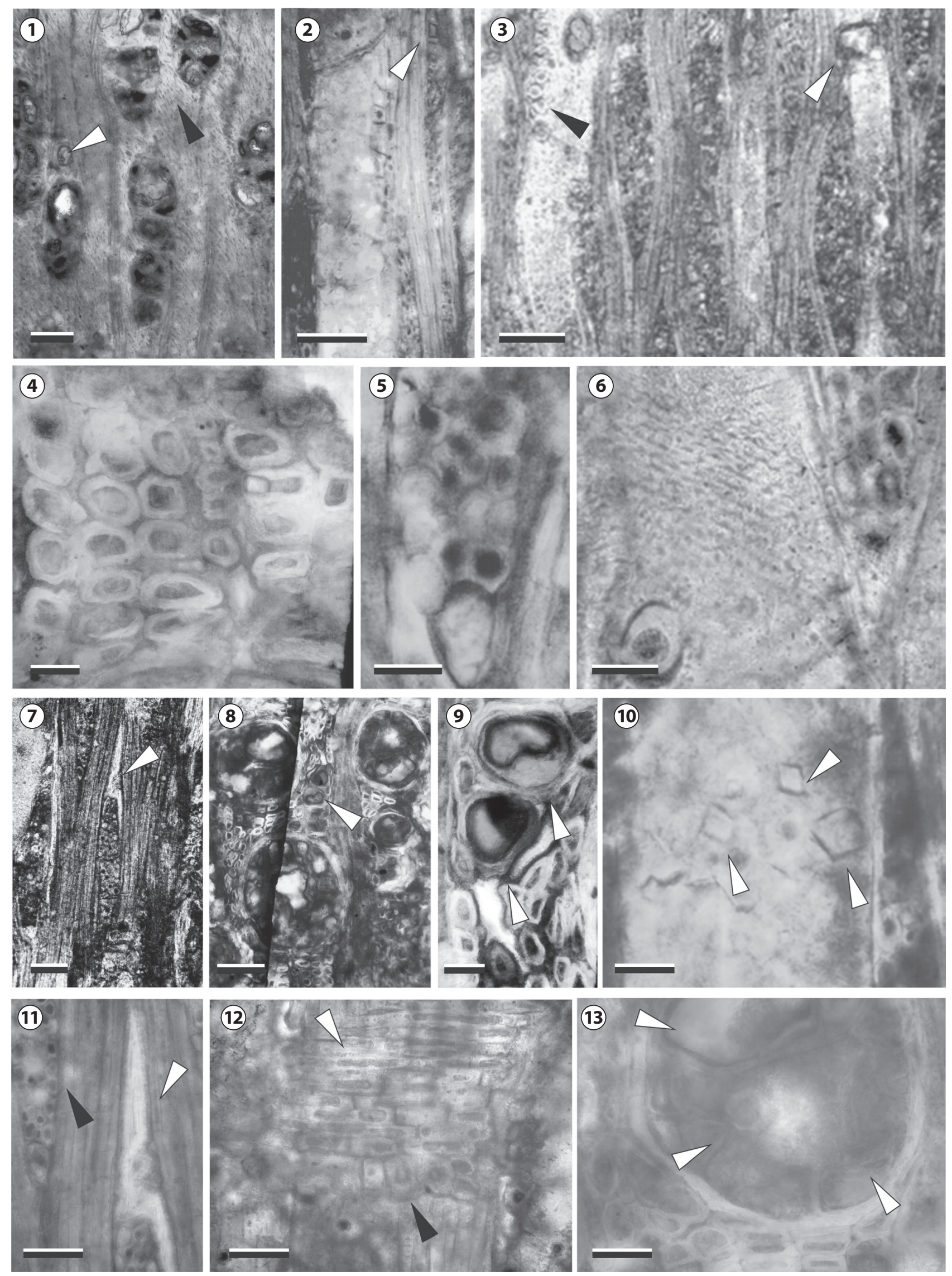
chmiedia en el diámetro de los vasos, la densidad de vasos por $\mathrm{mm}^{2}$, el diámetro de las fibras y en la presencia de cristales en los radios (Callado y Costa, 1997). Aunque algunos autores (Richter, 1981; Patel, 1987; Tressens, 1997; León y Espinoza De Pernía 2000; Parra, 2009) postularon que numerosas especies de Beilschmiedia están caracterizadas por la ausencia de cristales y por la presencia de sílice; otros autores (Richter, 1981, 1987; Callado y Costa, 1997) confirmaron la presencia de cristales en varias especies de este género.

Dos especies de Beilschmiedia de Nueva Zelanda, B. $t a-$ rairi (A. Cunn.) Kirk y B. tawa (A. Cunn.) Kirk, descriptas por Patel (1987) comparten una estrecha relación con el material fósil estudiado. Sin embargo, la primera se diferencia en el tipo de parénquima axial, que es bandeado y en la abundancia de células oleíferas. Con la segunda, se diferencia en el tipo de parénquima axial que es bandeado y abundante.

El material estudiado tiene una gran afinidad con Beilschmiedia taubertiana (Schw. y Mez) Kosterm, una especie endémica de los bosques atlánticos del sur de Brasil, caracterizada por presentar porosidad difusa, vasos solitarios (44\%), múltiples radiales de $2-4(51 \%)$ o agrupados (4\%), contorno circular a oval; vasos con un diámetro tangencial de $112(95-137) \mu \mathrm{m}$, una longitud de vasos de $503(20-2660) \mu \mathrm{m}$, con 8 a 14 vasos por $\mathrm{mm}^{2}$, placas de perforación simples, puntuaciones intervasculares alternas circulares o poligonales, fibras con un diámetro tangencial de 23 (19-29) $\mu \mathrm{m}$, parénquima axial vasicéntrico, aliforme y confluente, radios de 8 (6-11) por mm lineal, uniseriados compuestos por células cuadrangulares a verticales, 1-6 células de alto, y de 181 (85-322) $\mu \mathrm{m}$, y multiseriadas de 2-5 células de ancho, de 47 (26-75) $\mu \mathrm{m}$, radios homocelulares y heterocelulares compuestos por células procumbentes, cúbicas o verticales, cristales en radios y células oleíferas asociada al parénquima axial. Debido a la preservación del leño fósil no fue posible corroborar la presencia de puntuaciones radio-vasculares elongadas horizontalmente y diagonales, similares a las puntuaciones del parénquima y sílice y cristales de arenillas de sílice en células de los radios (Tressens, 1997).

Comparación con especies fósiles. Actualmente existe un amplio registro de especies fósiles pertenecientes a la familia Lauraceae, registradas desde el Cretácico hasta el Pleistoceno, tanto en el Hemisferio Norte como en el Hemisferio Sur (Wheeler y Manchester, 2002; InsideWood, 2004). En el presente trabajo seguimos los criterios propuestos por Dupéron et al. (2008) respecto a la sinonimia de Laurinium Unger 1845 y Ulminium Unger 1842 a Laurinoxylon Felix 1883. Los géneros más afines con el material fósil estudiado son: Laurinoxylon, Beilschmiedioxylon, Paraphyllanthoxylon Bailey 1924, Cryptocaryoxylon Leisman 1985 y Olmosoxylon Estrada-Ruiz, Martínez-Cabrera y Cevallos-Ferriz 2010 (Tab. 1). Del cuadro comparativo surge que Beilschmiedioxylon es el más afín al leño fósil estudiado. Este género monotípico fue descripto por Dupéron-Laudoueneix y Dupéron (2005) para el Mioceno de África y asignado a Beilschmiedioxylon africanum, caracterizado por presentar: porosidad difusa, vasos solitarios y múltiples radiales, placa de perforación simples, puntuaciones intervasculares alternas, parénquima paratraqueal vasicéntrico y a veces bandeado, radios 1-6 seriados, heterocelulares, de dos tipos, predominando los multiseriados de 4 células de ancho (95\%) y los uniseriados, escasos, constituidos por células verticales y presencia de cristales pequeños en las células de los radios. Sin embargo, el material bajo estudio se distingue principalmente en la distribución de las células oleíferas que en ésta especie son comunes en las fibras, el agrupamiento de los vasos, en el tamaño de las puntuaciones intervasculares que son de medianas a grandes $(10-12 \mu \mathrm{m})$, en la seriación de los radios y en el tipo de parénquima axial. Las puntuaciones radio-vasculares grandes y elongadas presentes en Beilschmiedioxylon africanum no pudieron ser observadas en el material estudiado debido a su preservación. La combinación única de caracteres diagnósticos que presenta el ejemplar fósil permitió la creación de una nueva entidad específica, Beilschmiedioxylon parataubertiana sp. nov.

Figura 2. Beilschmiedioxylon parataubertiana sp. nov., CID-PALBO 9, CID-PALBO mic. 163. 1, aspecto general mostrando vasos solitarios y múltiples radiales, parénquima axial vasicéntrico escaso (flecha negra) y "células oleíferas" en parénquima axial (flecha blanca)/ general view showing solitary vessels and in radial multiples, axial parenchyma vasicentric scarce (black arrow) and "oil cells" in axial parenchyma (white arrow); 2 , radios multiseriados con cristales romboidales (flecha)/ multiseriate rays with rhomboidal crystals (arrow); 3, radios multiseriados y elementos de vaso con tabiques horizontales a levemente oblicuos, placas de perforación simples (flecha blanca) y tilosis en formación (flecha negra)/ multiseriate rays and vessel elements with straight to oblique end walls (white arrow) and tyloses in formations (black arrow); 4 , detalle de fibras con paredes delgadas a gruesas/ detail of fibres thin- to thick-walled; 5, detalle de un radio heterocelular/ detail of a heterocellular ray; $\mathbf{6}$, detalle de las puntuaciones intervasculares/ detail of intervessel pits; 7, "célula oleífera" asociada a un radio multiseriado (flecha)/ "oil cells" in a multiseriate ray (arrow); 8 , vasos solitarios y "células oleiferas" (flecha)/ solitary vessels and "oil cells" (arrow); 9, "células oleíferas" mostradas en 8 (flechas)/ of "oil cells" showing in 8 (arrow); 10, detalle de cristales romboidales en el lumen de un vaso (flechas)/ detail of rhomboidal crystals in vessel lumen (arrow); 11, detalle de "célula oleífera" asociada a un radio multiseriado (flecha blanca) y radio multiseriado (flecha negra)/ detail of "oil cells" in a multiseriate ray (white arrow) and multiseriate ray (black arrow); 12, detalle de radio heterocellular constituido por células procumbentes (flecha blanca) y verticales o cúbicas (flecha negra)/ detail of heterocellular ray constituted by procumbent cells (white arrow) and upright and square cells (black arrow); 13. Detalle de tilosis (flechas)/ detail of tyloses (arrow). Corte transversal/ cross section: 1, 4, 8, 9, 13; Corte longitudinal tangencial/ tangential longitudinal section: 2, 3, 5, 6, 7, 10, 11; Corte longitudinal radial/ radial longitudinal section: 12 . Escala gráfica/ scale bar: 1-3, $7=100 \mu \mathrm{m} ; 4,6,8,11-13=20 \mu \mathrm{m} ; 5,9=30 \mu \mathrm{m} ; 10=10 \mu \mathrm{m}$. 
Orden Myrtales Reichenbach 1828

Familia Combretaceae R. Brown 1810

Género Terminalioxylon Schönfeld 1947

Especies tipo. Terminalioxylon naranjo Schönfeld 1947

\section{Terminalioxylon lajaum sp. nov. Figura 3.1-12}

Derivación del nombre. El epíteto específico, lajaum, hace referencia a la única palabra referida a un vegetal de la lengua Charrúa (pobladores originales de las costas del río Uruguay) "lajau": Ombú, hierba arborescente nativa, típica de las pampas argentinas y uruguayas, y que en lengua guaraní significa bella sombra.

Diagnosis. Porosidad difusa; los vasos se disponen en series múltiples radiales de 2-4 o más elementos, escasos a raros solitarios y agrupados; elementos de vaso pequeńos a medianos; placa de perforación simple; puntuaciones intervasculares pequeñas, alternas y de contorno redondeadas; radios uniseriados, algunos parcialmente biseriados formados por células agregadas; homogéneos constituido por células procumbentes; parénquima axial vasicéntrico, confluente a veces bandeado; fibras de paredes gruesas no septadas; cristales prismáticos en cámaras del parénquima axial, uno por cámara y ocasionalmente se observan en células de radios.

Diagnosis. Diffuse-porous; vessels multiples of 2-4 or more elements, scarce to rare solitary and clusters; small to medium vessels; perforation plate simple; intervessel pits small, alternate and rounded; rays uniseriate and some biseriate partially formed with cell aggregate; homocellular and composed of procumbent cells; axial parenchyma confluent, vasicentric and usually banded; fibres thick-walled and non-septate; prismatic crystals in chambered axial parenchyma cells, one per chamber and occasionally in rays cells.

Material tipo. CID-PALBO 10, CID-PALBO mic. 164 (tres preparados microscópicos).

Procedencia geográfica. Parque Nacional El Palmar, Entre Ríos, Argentina.

Procedencia estratigráfica. Formación El Palmar (Pleistoceno tardío).

Descripción. En corte transversal, los anillos de crecimiento son indistinguibles. La porosidad es difusa, con tendencia a una disposición tangencial. Los vasos son múltiples radiales de $2(25 \%), 3$ (31\%), 4 (23\%) o más (5\%) elementos, solitarios $(17 \%)$ y esporádicamente agrupados (8\%) (Fig. 3. 1, 3 ), son de contorno oval a circular. El diámetro tangencial

TABLA 1 - Cuadro comparativo de los géneros fósiles de Lauraceae más afines con Beilschmiedioxylon parataubertiana sp. nov./ Comparative chart of fossil genera of Lauraceae related to Beilschmiedioxylon parataubertiana sp. nov. Datos tomados de/ data taken from Bailey, 1924; Leisman, 1985; Dupéron-Laudoueneix y Dupéron, 2005; Dupéron et al., 2008; Estrada-Ruiz et al., 2010.

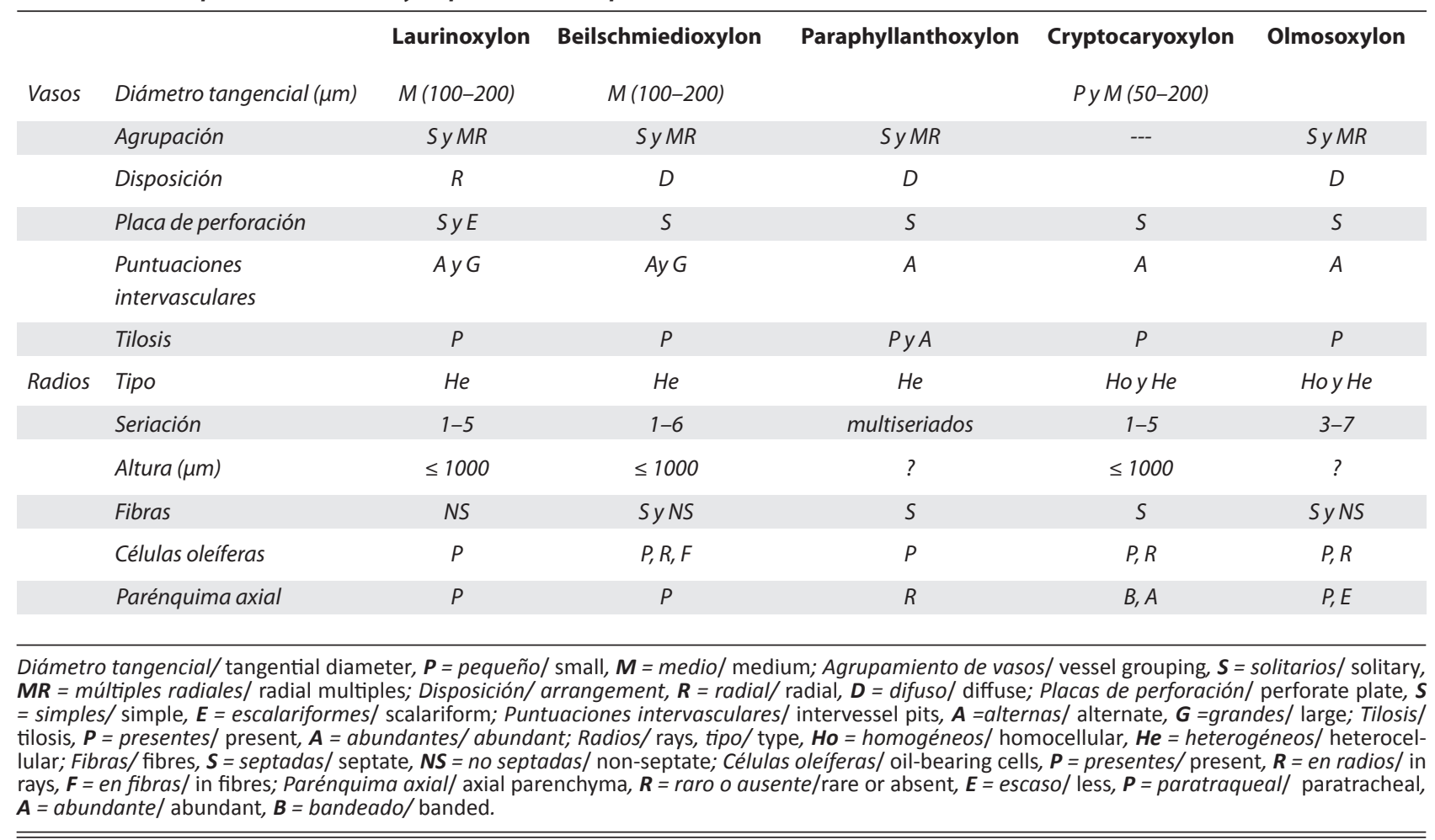


promedio es de $80(30-100) \mu \mathrm{m}$ y el diámetro radial promedio es de $62(20-110) \mu \mathrm{m}$. El espesor de la pared de los elementos vasales es de 9 (5-18) $\mu \mathrm{m}$ (Fig. 3.2, 3). La densidad es de 14 (6-20) por $\mathrm{mm}^{2}$. En algunos vasos se observa tilosis en formación (Fig. 3.6). El parénquima axial es vasicéntrico, confluente a veces bandeado, formando bandas con disposición tangencial estrecha continua y discontinua entre los vasos (Fig. 3.1-3). Las fibras están dispuestas radialmente (Fig. 3.3), tienen un contorno oval a circular (Fig. 3.3) con un diámetro de $16(10-40) \mu \mathrm{m}$, y un espesor de paredes de 5 (3-8) $\mu \mathrm{m}$, son de paredes gruesas y septadas.

En corte longitudinal tangencial, los elementos de vasos son cortos y de trayecto rectilíneo, con una longitud de 313 $(175-475) \mu \mathrm{m}$. Las placas de perforación son simples con tabiques horizontales y oblicuos ( $\geq 45^{\circ}$ ) (Fig. 3.4). Las puntuaciones intervasculares son pequeñas, alternas y de contorno redondeadas (Fig. 3.8, 9). Los radios son uniseriados y parcialmente biseriados con células agregadas (Fig. 3.5, 12). La altura de los radios es de 295 (225-380) $\mu \mathrm{m}$, y expresada en número de células es de 20 (12-27). Son numerosos con 17 (14-20) radios por mm lineal. Presentan cristales prismáticos en cámaras del parénquima axial, un cristal por cámara
(Fig. 3.11) y ocasionalmente se observan cristales en las células de los radios y depósitos oscuros (Fig. 3.10).

En corte longitudinal radial, los radios son homocelulares compuestos exclusivamente por células procumbentes (Fig. 3.7).

Comparación con especies actuales. El material estudiado comparte caracteres anatómicos con varias familias entre ellas, Myrtaceae, Meliaceae, Dipterocarpaceae y Combretaceae (Tortorelli, 1956; Metcalfe y Chalk, 1950a, 1950b; Van Vliet y Bass, 1984; InsideWood, 2004), y es con esta última donde fueron halladas las mayores similitudes (Tab. 2). Las Combretaceae se dividen en dos subfamilias: Combretoideae y Phonematoideae (Van Vliet y Baas, 1984), y el leño fósil en estudio tiene una relación estrecha con Combretoideae por poseer: porosidad difusa (raramente circular o semicircular) con patrón de distribución radial, vasos solitarios y/o múltiples radiales, vasos con diámetros entre 45 a $280 \mu \mathrm{m}$, y una longitud de 200 a $650 \mu \mathrm{m}$, placas de perforación simples, puntuaciones intervasculares alternas, radios generalmente uniseriados, a veces 2-3 seriados, heterogéneos a homogéneos, parénquima axial paratraqueal escaso, en algunos géneros aliforme, confluente o bandeado e infrecuentemente

TABLA 2 - Caracteres diagnósticos de las familias más afines a Terminalioxylon lajaum sp. nov./ Diagnostic characters of the families more related to Terminalioxylon lajaum sp. nov. Datos tomados de/ data taken from Tortorelli, 1956; Metcalfe y Chalk, 1950a, 1950b; Van Vliet y Bass, 1984; InsideWood, 2004.

\begin{tabular}{|c|c|c|c|c|}
\hline & Myrtaceae & Meliaceae & Combretaceae & Dipterocarpaceae \\
\hline Vasos & $\begin{array}{l}\text { Comúnmente pequeños, soli- } \\
\text { tarios a múltiples seriados }\end{array}$ & $\begin{array}{l}\text { Pequeños-medianos, } \\
\text { Múltiples radiales de 2-4 } \\
\text { elementos }\end{array}$ & $\begin{array}{l}\text { Medianos, solitarios o múlti- } \\
\text { ples radiales de } 4 \text { elementos }\end{array}$ & $\begin{array}{l}\text { Medianos, solitarios o } \\
\text { múltiples radiales de 2-3 } \\
\text { elementos }\end{array}$ \\
\hline Placa de perforación & $\begin{array}{l}\text { Simple, escalariforme en } \\
\text { algunas especies }\end{array}$ & Simple & Simple & Simple \\
\hline $\begin{array}{l}\text { Puntuaciones } \\
\text { intervasculares }\end{array}$ & Diminutas y alternas & Diminutas & Alternas & Alternas \\
\hline Parénquima axial & $\begin{array}{l}\text { Apotraqueal abundante } \\
\text { difuso y Aliforme difuso o } \\
\text { difuso agregado estrechos y } \\
\text { escasos }\end{array}$ & $\begin{array}{l}\text { Paratraqueal vasicéntri- } \\
\text { co, aliforme y confluente }\end{array}$ & $\begin{array}{l}\text { Aliforme confluente/vasicén- } \\
\text { trico y bandeado }\end{array}$ & $\begin{array}{l}\text { Abundante para- } \\
\text { traqueal aliforme }\end{array}$ \\
\hline Radios & Uniseriados/bi o triseriados & $\begin{array}{l}\text { Uniseriados/bio } \\
\text { triseriados }\end{array}$ & Uniseriados/bi a pentaseriado & $\begin{array}{l}\text { 4-8 seriados. Uniseria- } \\
\text { dos en Marquesia }\end{array}$ \\
\hline Cristales & $\begin{array}{l}\text { Presentes/ausentes, Algunas } \\
\text { especies presentan cristales } \\
\text { agrupados y drusas }\end{array}$ & Presentes & $\begin{array}{l}\text { Presentes/ausentes. Algunas } \\
\text { especies presentan cristales } \\
\text { agrupados y drusas }\end{array}$ & Ausentes \\
\hline Fibras & $\begin{array}{l}\text { Ocasionalmente septadas, } \\
\text { presencia de fibro-traqueidas } \\
\text { con o } \sin \text { septos }\end{array}$ & $\begin{array}{l}\text { Septadas en numerosos } \\
\text { géneros y pocas no } \\
\text { septadas }\end{array}$ & $\begin{array}{l}\text { Septadas, fibrotraqueidas } \\
\text { poco común }\end{array}$ & Simples \\
\hline $\begin{array}{l}\text { Canales } \\
\text { intervasculares }\end{array}$ & Presentes & Esporádicamente & Ocasional/presentes & $\begin{array}{l}\text { Característicos de todos } \\
\text { los géneros }\end{array}$ \\
\hline Traqueidas & Ausentes & Ausentes & Ausentes & Presentes \\
\hline
\end{tabular}


marginal, fibras septadas y presencia de cristales de forma variable tanto en células de los radios como en el parénquima axial, siendo raros en las fibras.
La familia Combretaceae está integrada por 20 géneros, y Terminalia L. es el género más relacionado con el material estudiado; caracterizado anatómicamente por presentar: poro-
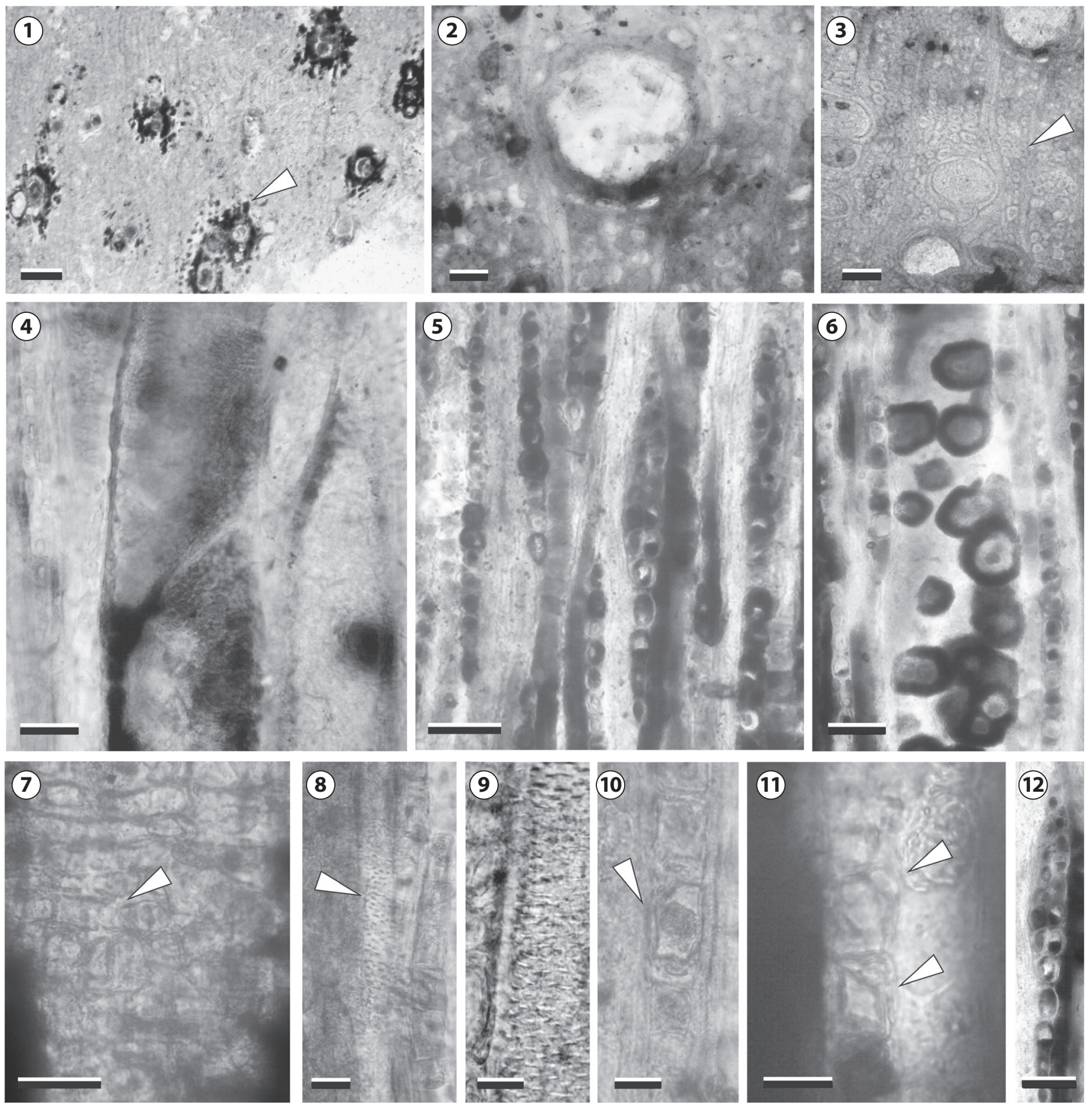

Figura 3. Terminalioxylon lajaum sp. nov. CID-PALBO 10, CID-PALBO mic. 164. 1, disposición de los vasos y párenquima axial vasicéntrico (flecha)/ vessel groupings and axial parenchyma vasicentric (arrow); $\mathbf{2}$, detalle de vaso solitario/ detail of solitary vessel; 3, disposición de las fibras (flecha), vasos solitarios y vasos múltiples radiales/ fibres groupins (arrow), solitary vessels and in radial multiples; 4 , detalle de un elemento de vaso con tabiques oblicuos/ detail of the vessel element with oblique end walls; $\mathbf{5}$, radios uniseriados y parcialmente biseriados/ uniseriate and partially biseriate rays; 6, tilosis en formación / tyloses in formation; 7, detalle de células procumbentes (flecha)/ detail of the procumbent cells (arrow); 8 , 9, detalle de las puntuaciones intervasculares (flecha)/ detail of the intervessel pits (arrow); 10, detalle de depósitos oscuros en radios uniseriados (flecha)/ detail of dark deposits in uniserite ray (arrow); 11, detalle de cristales prismáticos en cámaras del parénquima axial (flechas)/ detail of the prismatic crystals in chambered axial parenchyma cells (arrowheads); 12, detalle de un radio uniseriado con células agregadas/ detail of a uniserite ray with cells agregate. Corte transversal/ cross section: 1, 2, 3; Corte longitudinal tangencial/tangential longitudinal section: 4, 5, 6, 8, 9, 10, 11, 12; Corte longitudinal radial/ radial longitudinal section: 7 . Escala gráfica/ scale bar: $1=200 \mu \mathrm{m} ; 2-8,11=20 \mu \mathrm{m} ; 9-12=10 \mu \mathrm{m}$. 
sidad difusa, vasos en su mayoría de tamaño medianos, radios exclusivamente uniseriados aunque pueden observarse en pocas especies de 2-5 seriados, homocelulares y heterocelulares, cristales comúnmente presentes, fibras de longitud media y usualmente septadas y ocasionalmente presencia de canales traumáticos en algunas especies (Metcalfe y Chalk, 1950a). La localización y tipo de cristales son de importancia diagnostica en Terminalia (Détienne y Jacquet, 1983). Este carácter junto a el modo de agrupación de vasos, el tipo de radios y la presencia de cristales determinaron la afinidad del material fósil.

Dentro del género, comparte sus mayores similitudes con Terminalia obovata (Ruiz y Pav.) Steud., T. triflora (Griseb.) Lillo y $T$. australis Cambess. Con la primera comparte varias características comunes tales como anillos de crecimientos indistintos, vasos solitarios y múltiples radiales de 2-3 elementos, radios predominantemente homocelulares constituidos por células procumbentes y fibras septadas, pero difiere en el tipo de parénquima axial que es apotraqueal abundante y paratraqueal vasicéntrico abundante, y radios ocasionalmente heterocelulares con serie de células marginales. Con T. triflora, las semejanzas son la presencia de vasos de contorno oval a circular, con diámetro tangencial dentro de los rangos, fibras dispuestas radialmente y septadas, numerosos radios por $\mathrm{mm}$ lineal, uniseriados y muy raros uniseriados con células agregadas, del tipo homogéneos III de Kribs constituidos por células procumbentes, medidas de altura de radios próximos al ejemplar, cristales en células del parénquima y en las células de radio. No obstante posee una serie de diferencias a destacar ya que se tratan de caracteres que definen la especie como son: vasos predominantemente solitarios, de tamaño pequeño a mediano y muy largos, numerosos vasos por $\mathrm{mm}^{2}$ (15-30) y parénquima axial abundante.

Terminalia australis posee características tanto cualitativas como cuantitativas similares al leño fósil, tales como: diámetro tangencial de vasos y longitud de vasos, radios uniseriados, homogéneos III de Kribs, parénquima axial escaso bandeado en algunos sectores, fibras dispuestas radialmente y septadas y cristales en células de radios. En tanto que difiere en el predominio de vasos solitarios, y en las magnitudes de los mismos como la densidad de vasos, que es abundante (30-60) por $\mathrm{mm}^{2}$, el espesor de la pared de las fibras (7-10 $\mu \mathrm{m})$, pocos radios por $\mathrm{mm}$ lineal y un carácter diagnóstico importante, que es la presencia de cristales en las fibras. Los caracteres anatómicos más afines con el material fósil estudiado corresponden a la especie actual Terminalia australis y en menor medida con T. triflora y T. obovata.

Comparación con especies fósiles. El ejemplar fósil fue asignado a Terminalioxylon por presentar vasos de tamańo media- no a pequeños, con porosidad difusa, placas de perforación simples, puntuaciones intervasculares simples y alternas, parénquima axial usualmente paratraqueal y aliforme, ocasionalmente formando bandas, fibras libriformes y a menudo septadas, radios generalmente uniseriados, presentan diferentes tipos de cristales tanto en el parénquima axial, en células cuadradas de los radios y en células alargadas. En la Tabla 3 se muestran las comparaciones con las especies más afines de Terminalioxylon: T. naranjo Schönfeld 1947 del Mioceno de Colombia; T. porosum Schönfeld 1947 del Mioceno de Brasil; T. erichsenii Mussa 1958 del Plioceno de Brasil; T. portae Mirioni 1965 del Plioceno de Colombia; T. coriaceum Prakash y Awasthi 1969 del Plioceno de la India; T. edwardsii (Kräusel) Mädel-Angeliewa y Müller-Stoll 1973 del OligocenoMioceno de Europa y Asia; T. concordiensis Brea y Zucol 2001 del Pleistoceno Tardío de Argentina; Terminalia sp. en Pons y Franceschi (2007) del Mioceno de la Formación Pebas en Perú y T. panotlensis Castañeda-Posadas, Calvillo-Canadell y Cevallos-Ferriz 2009 del Mioceno de México (ver Tab. 3).

Es importante señalar que el material fósil posee una gran similitud con el ejemplar descripto por Wheeler et al. (2007) para el Mioceno de la Formación Bakate, Fejej, Etiopía, definido como Group IV Wood Type 6 y asignado con dudas a las familias Combretaceae? y Caesalpinoideae?. Las diferencias encontradas son la presencia de anillos de crecimiento demarcado, parénquima axial con bandas marginales y la presencia de canales traumáticos.

Terminalioxylon lajaum sp. nov. tiene una estrecha relación con Terminalioxylon erichsenii, y en menor medida con T. porosum y T. panotlensis (Tab. 3). Con el último se diferencia en el tipo de agrupación de los vasos y en el tipo de parénquima axial. La presencia de cristales estrictamente en radios en T. erichsenii y T. porosum, además del tipo de fibras y la abundancia de parénquima axial representan una diferencia significativa por lo que se propone una nueva entidad específica, Terminalioxylon lajaum sp. nov.

Orden Fabales Bromhead 1838

Familia FABACEAE Lindley 1836

Subfamilia Mimosoideae Candolle 1825

Género Piptadenioxylon Suguio y Mussa 1978

Especie tipo. Piptadenioxylon chimeloi Suguio y Mussa 1978

Piptadenioxylon chimeloi Suguio y Mussa 1978

Figuras 4.1-10

Material estudiado. CID-PALBO 8, CID-PALBO mic. 162 (tres preparados microscópicos). 
Procedencia geográfica. Parque Nacional El Palmar, Entre Ríos, Argentina.

Procedencia estratigráfica. Formación El Palmar (Pleistoceno tardío).

Descripción. En corte transversal, los anillos de crecimiento son indistinguibles. La porosidad es difusa. Los poros en su mayoría son solitarios (47\%) y en serie múltiples radiales de $2(31 \%)$ o 3 elementos (17\%), rara vez agrupados (5\%) (Fig. $4.1,6)$. El contorno de los mismos es oval a circular, con un espesor de pared de $8(6-10) \mu \mathrm{m}$. El diámetro tangencial promedio es de 77 (51-97) $\mu \mathrm{m}$ y el diámetro radial promedio es de 91 (51-127) $\mu \mathrm{m}$. La densidad de vasos por $\mathrm{mm}^{2}$ es de 21 (15-22). Los vasos presentan tilosis común e incrus- taciones de partículas oscuras (Fig. 4.6, 8). Los radios tienen trayecto lineal a levemente sinuoso. El parénquima axial es vasicéntrico y escaso (Fig. 4.1, 6). Las fibras son no septadas (Fig. 4.4), generalmente de contorno hexagonal raramente circular dispuestas en forma irregulares con tendencia a alinearse radialmente, sus puntuaciones son simples con un diámetro promedio de $10(7-13) \mu \mathrm{m}$, las paredes son gruesas y tienen un espesor promedio de 3 (1-4) $\mu \mathrm{m}$.

En corte longitudinal tangencial, los elementos de vasos poseen una longitud de $496(200-784) \mu \mathrm{m}$. Las placas de perforación son simples y los tabiques son oblicuos o lineales (Fig. 4.2, 4, 7), con puntuaciones intervasculares pequeñas, alternas (Fig. 4.10) y de contorno redondeadas con diámetro

Tabla 3. Comparación de Terminalioxylon lajaum con las especies fósiles más afines de Terminalioxylon/ Comparison of Terminalioxylon lajaum with the more closely related fossil species of Terminalioxylon. Datos tomados de/ data taken from Schönfeld, 1947; Mussa, 1958; Mirioni, 1965; Prakash y Awasthi, 1969; Mädel-Angeliewa y Müller-Stoll, 1973; Brea y Zucol, 2001; Pons y Franceschi, 2007; CastañedaPosadas et al., 2009.

\begin{tabular}{|c|c|c|c|c|c|c|c|c|c|c|}
\hline & $\begin{array}{c}\text { T. } \\
\text { lajaum }\end{array}$ & $\begin{array}{c}\text { T. } \\
\text { coriaceum }\end{array}$ & $\begin{array}{c}\text { T. } \\
\text { edwardsii }\end{array}$ & $\begin{array}{c}\text { T. } \\
\text { naranjo }\end{array}$ & T. $s p$ & $\begin{array}{c}\text { T. } \\
\text { erichsenii }\end{array}$ & $\begin{array}{c}\text { T. } \\
\text { porosum }\end{array}$ & $\begin{array}{c}\text { T. } \\
\text { portae }\end{array}$ & $\begin{array}{c}\text { T. } \\
\text { concordiensis }\end{array}$ & $\begin{array}{c}\text { T. } \\
\text { panotlensis }\end{array}$ \\
\hline$A C$ & 1 & 1 & 1 & 1 & I & 1 & 1 & $I O D$ & $D$ & $D$ \\
\hline Porosidad & $D$ & DySC & $D$ & $D$ & $D$ & $D$ & $D$ & $D$ & $D$ & $D$ \\
\hline $\begin{array}{l}\text { Agrupación } \\
\text { de vasos }\end{array}$ & $\begin{array}{c}M R 2-3 \\
\text { o } 4 \text { yS } \\
(17 \%)\end{array}$ & $A$ & & & & SyMR 2-4 & $M R \circ A$ & & $\begin{array}{c}S, \text { a veces } M R \\
2-3\end{array}$ & $\begin{array}{c}S(90 \%), M R \\
2-3\end{array}$ \\
\hline$D T \mu m$ & $\begin{array}{c}80(30- \\
100)\end{array}$ & $100-200$ & $100-200$ & $\begin{array}{l}100- \\
\geq 200\end{array}$ & $100-200$ & $\geq 200$ & $100-200$ & $100-200$ & $180(104-224)$ & $110(90-135)$ \\
\hline $\begin{array}{l}\text { Densidad } \\
\text { por } m m^{2}\end{array}$ & $6-20$ & $\leq 5$ & $5-20$ & $5-20$ & $\leq 5$ & $\leq 5$ & $\leq 5$ & $\leq 5$ & $9(5-16)$ & $13(9-14)$ \\
\hline$L \mu m$ & $\begin{array}{c}312(175- \\
475)\end{array}$ & $\leq 350$ & $\leq 350$ & $350-800$ & $350-800$ & $170-600$ & $350-800$ & $\leq 350$ & $176-560$ & $300(80-440)$ \\
\hline Tilosis & $P C$ & C & --- & C & --- & PCaC & $C$ & $?$ & --- & $A$ \\
\hline Fibras & $S$ & $S$ & --- & --- & $S$ & NS & --- & --- & $S$ & $S$ \\
\hline $\begin{array}{l}\text { Parénquima } \\
\text { axial }\end{array}$ & $V, C, B$ & $V, A, C, D$ & $C, B$ & $V, A, C$ & $V, A, C$ & $A, C$ & $V, A, C$ & $V, A, C, B$ & $D, V, A$ & \\
\hline Radios, Tipo & Ho & $\mathrm{He}$ & $\mathrm{He}$ & Ho & $\mathrm{He}$ & Hoу $\mathrm{He}$ & Ho & Hoу $\mathrm{He}$ & HoуHe & Ho \\
\hline $\begin{array}{l}\text { Radios, } \\
\text { seriación }\end{array}$ & 1 & & $1-3$ & $1-3$ & 1 & $1-2$ & 1 & $1-3$ & $1-2$ & 1 \\
\hline $\begin{array}{l}\text { Radios por } \\
\text { mm lineal }\end{array}$ & $\begin{array}{c}17 \\
(14-20)\end{array}$ & $\geq 12$ & $4-+12$ & $4-12$ & $4-12$ & $\geq 12$ & $\geq 12$ & $\geq 12$ & $4-8$ & $10(7-12)$ \\
\hline Cristales & $P A y R$ & $P A$ & $P A y R$ & $R$ & $R$ & $R$ & $R$ & $R$ & $P A y R$ & --- \\
\hline $\begin{array}{l}\text { Canales in- } \\
\text { tercelulares }\end{array}$ & --- & --- & $P$ & --- & --- & --- & --- & --- & $P$ & --- \\
\hline
\end{tabular}

$\boldsymbol{A C}=$ Anillos de crecimiento/ growth rings, $\boldsymbol{I}=$ indistinguibles/ indistict, $\boldsymbol{D}=$ distinguibles/distinct; porosidad $/$ porosity, $\boldsymbol{D}=$ difusa/diffuse, $\mathbf{S C}=$ semicircular/semi-ring; Agrupación de vaso/vessel grouping, $\mathbf{S}=$ solitarios/ solitary; $\boldsymbol{M} \boldsymbol{R}=$ múltiples radiales/ radial multiples; $\boldsymbol{A}=$ agrupados/ clusters; $\boldsymbol{D} \boldsymbol{T}$ $=$ Diámetro tangencial en $\mu \mathrm{m} /$ tangential diameter in $\mu \mathrm{m} ; \boldsymbol{L}=$ Longitud en $\mu \mathrm{m} /$ length in $\mu \mathrm{m} ;$ Fibras/ fibres, $\boldsymbol{S}=$ septadas/ septate, $\boldsymbol{N S}=$ no septadas/ non-septate; Tilosis/tyloses, $\boldsymbol{P}=$ poco común/ uncommon, $\boldsymbol{C}=$ común/ common, $\boldsymbol{A}=$ abundante/ abundant; Parénquima axial/ axial parenchyma, $\boldsymbol{V}=$ vasicéntrico/ vasicentric, $\boldsymbol{A}=$ aliforme/ aliform, $\boldsymbol{C}=$ confluente/ confluent, $\boldsymbol{B}=$ bandeado/ banded, $\boldsymbol{D}=$ difuso/diffuse, $\boldsymbol{M}=$ marginal/ marginal; radios/ rays, tipo/type, $\boldsymbol{H o}=$ homogéneos/ homogeneous, $\boldsymbol{H e}=$ heterogéneos/ heterogeneous; Cristales/ crystals, $\boldsymbol{P A}=$ en parénquima axial/ in axial parenchyma, $\boldsymbol{R}=$ en radios/ in rays, Canales intercelulares/intercellular canals, $\boldsymbol{P}=$ presentes/ present. 
promedio de $7(5-10) \mu \mathrm{m}$. Se observa parénquima septado de 1-5 células (Fig. 4. 8). Los radios son en su mayoría triseriados $(85 \%)$ (Fig. 4. 4, 9) siendo muy escasos los multiseriados de 4 células de ancho (15\%) (Fig. 4. 2). La altura de los radios es de 265 (203-330) $\mu \mathrm{m}$ y expresado en número de células es de 16 (19-23). El ancho de los radios es 43 (25-76) $\mu \mathrm{m}$. Los radios son del tipo homogéneo I de Kribs (Fig. 4. 4), son pocos a moderadamente pocos de 6 (3-7) radios por mm lineal.

En corte longitudinal radial, los radios son homocelulares, constituidos exclusivamente por células procumbentes (Fig. 4. 5).

Comparación con especies actuales. La combinación de vasos solitarios y múltiples radiales, placa de perforación simple, parénquima axial abundante y confluente o bandeado, radios uniseriados o raramente biseriados, homocelulares compuestos por células procumbentes y fibras no septadas ocurren en las Mimosoideae (Cozzo, 1951; Baretta-Kuipers, 1981; Wheeler y Baas, 1992; Evans et al., 2006).

Los dos géneros actuales más afines al material estudiado son: Parapiptadenia Brenan y Piptadenia Benth. En la Tabla 4 se detallan los caracteres anatómicos afines con el material fósil estudiado (Cozzo, 1951; Tortorelli, 1956; Metcalfe y Chalk, 1950a; Evans et al., 2006).

Comparación con especies fósiles. Los géneros fósiles asignados a la subfamilia Mimosoideae son numerosos y el leño fósil fue asignado a Piptadenioxylon (InsideWood, 2004; ver tab.1, p. 40 en Brea et al., 2010). Piptadenioxylon chimeloi (Tab. 4) se caracteriza por presentar porosidad difusa, vasos solitarios raramente múltiples radiales cortos, con contenidos oscuros, pequeńos a medios, con diámetros entre 45 a $100 \mu \mathrm{m}$, numerosos (15 a 21 por $\mathrm{mm}^{2}$ ); elementos de los vasos con paredes terminales horizontales o inclinados de 100 a $140 \mu \mathrm{m}$ de longitud; placas de perforación simples; puntuaciones intervasculares pequeñas, alternas; parénquima axial vasicéntrico y disperso alrededor de los vasos en forma irregular; radios $2-3$ seriados, numerosos de 20 a 30 por $\mathrm{mm}^{2}$, homogéneos tipo I de Kribs y fibras con puntuaciones simples y no septadas (Suguio y Mussa, 1978).

\section{CONSIDERACIONES FINALES}

El registro de leños fósiles de la Formación El Palmar es conocido por la excelente preservación de sus permineralizaciones. Se conocen hasta la fecha 14 taxones que fueron reportados en trabajos previos. Esta información paleobotánica, junto con los datos paleoecológicos y paleoclimatológicos, demostró la existencia durante parte del Pleistoceno tardío en el noreste de Argentina de bosques mixtos húmedos, bosques mixtos semi-áridos y palmares. Estos bosques estaban integrados por elementos característicos de una paleoflora subtropical y tropical, que vivió bajo un clima cálido y húmedo a semi-árido (Brea et al., 2010; Brea y Zucol, 2011 y referencias allí citadas).

Elementos característicos tales como Lauraceae, Combretaceae y Myrtaceae podrían haber crecido en bosques en galería, vinculados a la llanura de inundación del río Uruguay. Este tipo de vegetación se caracteriza por un microclima que facilita la disponibilidad permanente de humedad, donde el agua modera la temperatura y reduce la amplitud térmica, facilitando así la aparición de vegetación abundante debido a que no depende de las precipitaciones para obtener este recurso (Brea, 1998; Brea y Zucol, 2001; Brea et al., 2001).

Las Anacardiaceae y las Fabaceae indicarían la presencia de bosques semi-áridos a áridos. Estos bosques se habrían desarrollado en zonas altas, de suelos maduros y no anegados (Lutz, 1979; Brea, 1999; Brea et al., 2010). La predilección de las leguminosas por hábitos semi-áridos a áridos está relacionado con el metabolismo del nitrógeno (McKey, 1994).

Los palmares integrados por taxones afines a las subfamilias Coryphoideae y Arecoideae, son elementos característicos de la flora subtropical-tropical. La abundancia de estípites fósiles en grandes áreas del centro-este de la provincia de Entre Ríos soporta el argumento de la existencia de extensivas áreas de palmares (Lutz, 1980, 1984, 1986; Zucol et al., 2005).

Este trabajo incrementa el listado paleoflorístico con las descripciones y asignaciones de nuevos taxones fósiles para la Formación El Palmar: Beilschmiedioxylon parataubertiana sp. nov., Terminalioxylon lajaum sp. nov. y Piptadenioxylon chimeloi.

Beilschmiedioxylon parataubertiana sp. nov. es un fósil con afinidad al género pantropical Beislchmiedia, constituido por 250 especies (Rohwer, 1993), de las cuales 6 se encuentran distribuidas en los bosques del sudeste de Brasil (Callado y Costa, 1997) y en la actualidad no está presente en Argentina (Zuloaga et al., 1999). Beilschmiedia taubertiana, la especie más afín al leńo fósil, es endémica de Brasil y un componente de la Mata Atlántica (Nishida, 1999).

El género Terminalia comprende unas 200 especies que habitan los trópicos y subtrópicos de Asia, norte de Australia, Polinesia, África, América Central y del Sur (Gentry, 1996; Contí et al., 1997). Terminalioxylon lajaum sp. nov. presenta afinidad con la especie actual Terminalia australis, especie arbórea hidrófita que crece en las selvas marginales del sur de Brasil, Paraguay, Uruguay y noreste de Argentina, bajo un clima cálido a templado-cálido (Tortorelli, 1956; IBODA, 1994). 

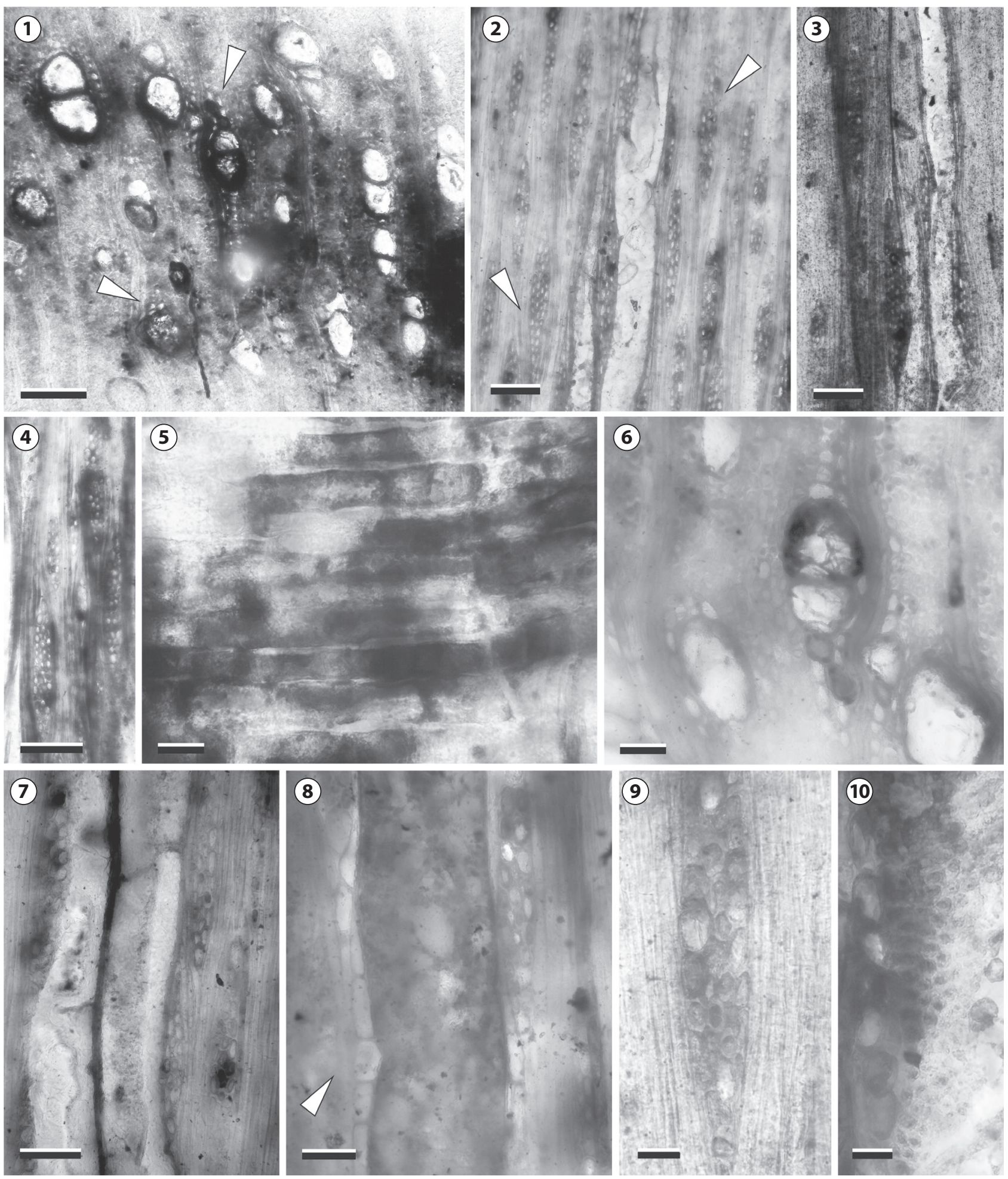

Figura 4. Piptadenioxylon chimeloi CID-PALBO 8, CID-PALBO mic. 162. 1, vista general mostrando disposición de vasos y parénquima axial vasicéntrico escaso (flechas)/ view general showing vessel groupings and axial parenchyma vasicentric scarce (arrow); 2 , radios multiseriados (flechas)/ multiserite rays (arrow); 3, detalle de radios y elemento de vasos/ detail of rays and vessel element; $\mathbf{4}$, radios homogéneos y fibras no septadas/ homogenous rays and non-septate fibres; $\mathbf{5}$, detalle de las células procumbentes/ detail of the procumbent cells; $\mathbf{6}$, detalle de vasos y párenquima axial vasicéntrico escaso/ detail of vessels and axial parenchyma vasicentric scarce; $\mathbf{7}$, detalle de un elemento de vaso largo y tabiques rectos a oblicuos/ detail of a large vessel element with straight to oblique end walls; 8 , parénquima septado (flecha) y vasos con depósitos/ parenchyma in strand (arrow) and deposits in vessel; $\mathbf{9}$, detalle de un radios triseriado/ detail of a triserite ray; 10, detalle de puntuaciones intervasculares/ detail of the intervessel pits. Corte transversal/ cross section: 1, 6; Corte longitudinal tangencial/ tangential longitudinal section: 2, 3, 4, 7, 8, 9, 10; Corte longitudinal radial/ radial longitudinal section: 5 . Escala gráfica/ scale bar: $1-4$ y $7=100 \mu \mathrm{m} ; 5-10=20 \mu \mathrm{m}$. 
Piptadenioxylon chimeloi es afín a los géneros actuales Parapiptadenia y Piptadenia, el primero con una distribución en las áreas subtropicales-tropicales de América del Sur y el segundo con una distribución más extensa abarcando zonas tropicales y subtropicales del Caribe, América Central y América del Sur. Ambas predominan en los bosques húmedos de las selvas tropicales atlánticas, Selva misionera, Yungas en el noroeste Argentina y en ambientes semiáridos-áridos, como es el caso de Parapiptadenia excelsa que en la Argentina se extiende por las provincias de Catamarca, Salta, Jujuy hasta Bolivia (Tortorelli, 1956; Cabrera, 1976; Fedalto et al., 1989; IAWA Committee, 1989; IBODA, 1994; McKey, 1994; Richter y Dallwitz, 2000; Santos-Filho et al., 2011).

Se calcularon los índices de Vulnerabilidad (V) y Mesomorfía (M) propuestos por Carlquist (1977) para los leños fósiles estudiados. Los valores de V para Beilschmiedioxylon parataubertiana sp. nov. es de 9; para Terminalioxylon lajaum sp. nov. de 5,71 y Piptadenioxylon chimeloi dio un valor de 3,67. Los valores de M dieron 3114, 1787 y 1818 respectivamente. Comparando las tres especies se llegó a la conclusión que la Fabaceae resultó ser el taxón que mostró cierto grado de xeromorfía debido a una diferencia mínima respecto a los valores de índice obtenidos, mientras que las Lauraceae y Combretaceae dieron valores que indicarían que las plantas fueron mesofíticas y que se habrían desarrollado bajo un buen régimen hídrico en condiciones cálidas.

El registro de Beilschmiedioxylon parataubertiana sp. nov. y Piptadenioxylon chimeloi, dos taxones afines a Beilschmiedia taubertiana y Parapiptadenia, en la Formación El Palmar amplía el área de distribución florística y estarían indicando un clima más cálido que el actual para esta región.

Apoyan estas inferencias la interpretación del registro sedimentario aflorante en la barranca del río Uruguay, que indica un clima húmedo y cálido durante la depositación de gran parte de la Formación El Palmar (Iriondo y Kröhling, 2008; Kröhling, 2009). El análisis de facies sedimentarias indica un ambiente estrechamente vinculado a un complejo fluvial de llanura, con dominio de arena con alta madurez mineralógica y presencia de lentes gravosas que indican alta energía de transporte. El color general rojo a amarillo de la unidad evidencia movilización generalizada de sesquióxidos de hierro bajo un clima tropical (Kröhling, 2009)

TABLA 4 - Comparación de Piptadenioxylon chimeloi con los géneros actuales más afines/ Comparison of Piptadenioxylon chimeloi with closely extant genera. Datos tomados de/ data taken from Cozzo, 1951; Tortorelli, 1956; Metcalfe y Chalk, 1950 b; Evans et al., 2006.

\begin{tabular}{|c|c|c|c|c|c|}
\hline & & Parapiptadenia & Piptadenia & $\begin{array}{c}\text { P. chimeloi } \\
\text { Suguio y Mussa } 1978\end{array}$ & $\begin{array}{l}\text { P. chimeloi } \\
\text { este trabajo }\end{array}$ \\
\hline \multicolumn{2}{|c|}{ Anillos de crecimiento } & $D / l$ & $D / l$ & & 1 \\
\hline \multirow[t]{5}{*}{ Vasos } & Diámetro tangencial $(\mu m)$ & $112-123$ & $54-170$ & $45-100$ & $51-96$ \\
\hline & Densidad & $23-30$ & $13-50+$ & $15-20$ & $15-22$ \\
\hline & Múltiples radiales & $\mathrm{O} / \mathrm{MC}$ & $R / C$ & $R$ & 0 \\
\hline & Agrupados & $R / O$ & $R / F$ & $A$ & $O$ \\
\hline & Puntuaciones intervasculares $(\mu \mathrm{m})$ & $3-9$ & $4-12$ & --- & $5-10$ \\
\hline \multirow[t]{2}{*}{ Fibras } & Espesor de pared & $M / G$ & G & G & $M / G$ \\
\hline & Septadas & $P / A$ & $P$ & $A$ & $A$ \\
\hline \multicolumn{2}{|c|}{ Parénquima axial } & $V, A$ & $V, B$ & $V$ & $V$ \\
\hline \multirow[t]{5}{*}{ Radios } & Altura en número de células & $11-24$ & $12-24$ & --- & 16 \\
\hline & Ancho $(\mu m)$ & $3-45$ & $2-62$ & --- & $25-76$ \\
\hline & Pormm lineal & $8-10$ & $5-13$ & $25-30$ & $3-7$ \\
\hline & Seriación & $1-3$ & $1-2(4)$ & $1-3$ & 3 \\
\hline & Tipo & $\mathrm{Ho} / \mathrm{He}$ & $\mathrm{Ho} / \mathrm{He}$ & Ho & Ho \\
\hline \multicolumn{2}{|c|}{ Cristales prismáticos } & $P / A$ & $P$ & $A$ & $?$ \\
\hline
\end{tabular}

Anillos de crecimiento/ growth ring, $\mathbf{D}=$ distinguibles/distinct, I = indistinguibles/ indistict; Agrupación de vasos/vessel groupings, Múltiples radiales/ radial multiples, Agrupados/clusters, $\mathbf{O}=$ ocasionalmente/occasionaly, $\mathbf{F}=$ frecuentes $/$ frequent, $\mathbf{M C}=$ muy comunes $/ \mathrm{more}$ common, $\mathbf{C}=$ comunes $/$ common, $\boldsymbol{R}=$ raros/rare, $\boldsymbol{A}=$ ausentes/absent; $\boldsymbol{P I}=$ Punteaduras intervasculares/intervessel pits; Fibras/fibres, $\boldsymbol{M}=$ paredes medianas/ thin- to thick-walled, $\mathbf{G}=$ paredes gruesas/thick-walled; Parénquima axial/ axial parenchyma, $\mathbf{V}=$ vasicéntrico/ vasicentric; $\boldsymbol{A}=$ aliforme/ aliform; $\boldsymbol{B}=$ bandeado/banded; $R a-$ dios/ rays, Tipo/type, $\mathbf{H o}=$ homocelulares/ homocellular, $\mathbf{H e}=$ heterocelulares/ heterocellular; Cristales prismáticos/ prismatic crystals, $\boldsymbol{P}=$ presentes/ present, $\boldsymbol{A}=$ ausentes/absent. 
La asociación de vertebrados registrada en esta formación (Ferrero et al., 2007; Brandoni et al., 2010), excluyendo a Tapirus $\mathrm{cf}$. T. terrestris L. 1758, está asociada a pastizales. T. terrestris es usualmente vinculado con bosques subtropicales húmedos o sabanas subtropicales asociado a cursos de agua permanente, en climas húmedos y cálidos (Brandoni et al., 2010).

Los análisis morfométricos realizados por Brandoni et al. (2010) en ejemplares de Mylodon darwini Owen 1839 indicaron que el pequeño tamaño corporal estaría vinculado con las condiciones de clima cálido en esta región. Los estudios basados sobre la distribución geográfica y estratigráfica de Mylodon (ver referencias en Brandoni et al., 2010) indican que este género vivió en climas fríos y áridos a semi-áridos. Sin embargo, la presencia de este taxón en períodos interglaciales y en períodos glaciales podrían indicar que esta especie tenía una gran tolerancia ecológica, capaz de habitar desde zonas áridas a semi-áridas y frías hasta húmedas y cálidas, e incluso en ambientes fríos y montańosos (Brandoni et al., 2010).

Teniendo en cuenta los registros paleobotánicos, junto con los registros de vertebrados, los indicadores sedimentológicos, estratigráficos y geomorfológicos y las edades absolutas obtenidas en la Formación El Palmar, se infiere que durante la depositación de gran parte de dicha formación geológica las condiciones climáticas fueron cálidas y húmedas.

Los datos paleobotánicos presentados aquí y los trabajos previos (Brea y Zucol, 2011 y referencias allí citadas) soportan el argumento que estas especies formaban parte de un ambiente heterogéneo. Los leños fósiles avalan la existencia de bosques mixtos ribereńos, donde Beilschmiedioxylon parataubertiana sp. nov. y Terminalioxylon lajaum sp. nov. serían componentes de esta paleocomunidad y bosques mixtos húmedos a semi-áridos con la presencia de Piptadenioxylon chimeloi, un integrante de las Fabaceae. Estos últimos indican un ambiente diferencial relacionado con factores particulares, como topografía y/o humedad.

\section{AGRADECIMIENTOS}

Este trabajo forma parte de la Tesis Doctoral en ejecución en la Universidad Nacional de Córdoba de una de las autoras (R.S. Ramos). Los fondos fueron provistos por el proyecto PICT 2008 N0176 de la Agencia Nacional de Promoción Científica y Tecnológica. A A. Lutz y R. Tadeu Bolzon por sus aportes para mejorar el manuscrito original en calidad de árbitros, así como también al Comité Editor de la revista. A las autoridades de la Administración de Parques Nacionales por la autorización de Investigación $\left(\mathrm{N}^{\circ}\right.$ de orden DCM406, DCM406 RnvNEA 1 DCM406 RnvNEA 2).

\section{BIBLIOGRAFÍA}

APG, III. 2009. An update of the Angiosperm Phylogeny Group classification for the orders and families of flowering plants: APG III. Botanical Journal of the Linnean Society 161: 105-121.
Ameghino, F. 1888. Rápidas diagnosis de algunos mamíferos fósiles nuevos de la República Argentina. P. E. Coni, Buenos Aires, 17 p.

Bailey, I.W. 1924. The problem of identifying the wood of cretaceous and later Dicotyledons: Paraphyllanthoxylon arizonense. Annals of Botany 38: 439-452.

Baretta-Kuipers, T. 1981. Wood Anatomy of Leguminosae: its relevance to taxonomy. En: R.M. Polhill y P.H. Raven (Eds.), Advances in Legume Systematic 2. The Royal Botanical Gardens, Kew, p. 677-705.

Bossi, J. 1969. Geología del Uruguay. Universidad de la República, Departamento de Publicaciones. Colección Ciencias 12. $2^{\circ}$ Edición, Montevideo, $464 \mathrm{p}$.

Brandoni, D., Ferrero, B.S. y Brunetto, E. 2010. Mylodon darwini Owen (Xenarthra, Mylodontinae) from the Late Pleistocene of Mesopotamia, Argentina, with remarks on individual variability, paleobiology, paleobiogeography, and paleoenvironment. Journal of Vertebrate Paleontology 30: $1547-1558$

Brea, M. 1998. Ulminium mucilaginosum n.sp. y Ulminium artabeae n.sp., Dos leños fósiles de Lauraceae en sedimentos de la Formación El Palmar, provincia de Entre Ríos, Argentina. Ameghiniana 35: 193-204.

Brea, M. 1999. Leños fósiles de Anacardiaceae y Mimosaceae de la Formación El Palmar (Pleistoceno superior), del Departamento Concordia, provincia de Entre Ríos. Ameghiniana 36: 63-69.

Brea, M., Zucol, A.F. y Scopel, A. 2001. Estudios paleobotánicos del Parque Nacional El Palmar (Argentina): I. Inclusiones minerales en leńos fósiles de Myrtaceae. Natura Neotropicalis 32: 33-40.

Brea, M. y Zucol, A.F. 2001. Maderas fósiles de Combretaceae de la Formación El Palmar (Pleistoceno), provincia de Entre Ríos, Argentina. Ameghiniana 38: 499-417.

Brea, M. y Zucol, A. 2011. The Paraná-Paraguay Basin: Geology and Paleoenvironments. En: J. Albert y R. Reis (Eds.), Historical Biogeography of Neotropical Fresh Water Fishes. University of California Press, Berkeley, p. 69-87.

Brea, M., Zucol, A.F. y Patterer, N. 2010. Fossil woods from late Pleistocene sediments from El Palmar Formation, Uruguay Basin, eastern Argentina. Review of Palaeobotany and Palynology 163: 35-51.

Cabrera, A. 1976. Regiones Fitogeográficas Argentinas. En: Enciclopedia argentina de agricultura y jardinería. Tomo II. Fascículo 1. ACME, Buenos Aires.

Callado, C. y Costa, C. 1997. Wood anatomy of some Anaueria and Beilschmiedia species (Lauraceae). IAWA Journal 18: 247-259.

Carlquist, S. 1977. Ecological factors in wood evolution: a floristic approach. American Journal of Botany 64: 887-896.

Carlquist, S. 2001. Comparative wood anatomy. Systematic, ecological, and evolutionary aspects of dicotyledon wood. Springer Series in Wood Science, Springer, $448 \mathrm{p}$.

Castañeda-Posadas, C., Calvillo-Canadell, L. y Cevallos-Ferriz, S. 2009. Woods from Miocene sediments in Panotla, Tlaxcala, Mexico. Review of Palaeobotany and Palynology 156: 494-506.

Chattaway, M. 1932. Proposed standards for numerical values used in describing woods. Tropical Woods 29: 20-28.

Contí, E., Litt, A., Graham, S., Briggs, B. y Johnson, A. 1997. Interfamilial relationships in Myrtales: molecular phylogeny and patterns of morphological evolution. Systematic Botany 22: 629-647.

Cozzo, D. 1951. Anatomía del leño secundario de las leguminosas Mimosoideas y Cesalpinoideas Argentinas silvestres y cultivadas. Instituto Nacional de Investigaciones de las Ciencias Naturales y Museo Argentino Bernardino Rivadavia, Ciencias Botánicas 2: 63-146.

Détienne, P. y Jacquet, P. 1983. Atlas d'identification des bois de l'amazonie et des regions voiseines. Centre Technique Forestier Tropical, Nogent s/ Marne, $640 \mathrm{p}$.

Dupéron-Laudoueneix, M. y Dupéron, J. 2005. Bois fossiles de Lauraceae: nouvelle découverte au Cameroun, inventaire et discussion. Annales de Paléontologie 91: 127-151.

Dupéron, J., Dupéron-Laudoueneix, M., Sakala, J. y De Franceschi, D. 2008. Ulminium diluviale Unger: historique de la découverte et nouvelle étude. Annales de Paléontologie 94: 1-12. 
Estrada-Ruiz, E, Martínez-Cabrera, H. y Cevallos-Ferriz, S. 2010. Upper Cretaceous woods from the Olmos Formation (late campanian-early Maastrichtian), Coahuila, Mexico. American Journal of Botany 97: 1179-1194.

Evans, J., Gasson, P. y Lewis, G. 2006. Wood anatomy of the Mimosoideae (Leguminosae). IAWA Journal. Supplement 5, $117 \mathrm{p}$.

Farr, E.R. y Zijlstra, G., (Eds.), 1996. Index Nominum Genericorum (Plantarum). http://botany.si.edu/ing/ (consulta Septiembre, 2011).

Fedalto, L., Mendes, I.da C. y Coradin, V.T.R. 1989. Madeiras da Amazonia. Descricao do lenho de 40 especies ocorrentes na Floresta Nacional do Tapajos. Instituto Brasileiro do Meio Ambiente e dos Recursos Naturais Renováveis-IBAMA: Brasilia, 156 p.

Felix, J. 1883. Untersuchungen über fossile Hölzer. I. Zeitschrift der Deutschen Geologischen Gesellschaft 35: 59-92.

Ferrero, B., Brandoni, D., Noriega, J.I. y Carlini, A.A. 2007. Mamíferos de la Formación El Palmar (Pleistoceno tardío) de la provincia de Entre Ríos, Argentina. Revista del Museo Argentino de Ciencias Naturales n.s. 9: 109-117.

Gentry, A. 1996. A field guide to the families and genera of woody plants of Northwest South America (Colombia, Ecuador, Perú), Second Edition. The University of Chicago Press, Chicago, 895 p.

Gregory, M. 1994. Bibliography of systematic wood anatomy of dicotyledons. IAWA Journal, Supplement 1: 1-265.

Gregory, M., Poole, I. y Wheeler, E. 2009. Fossil dicot wood names, an annotated list with full bibliography. IAWA Journal, Supplement 6: 1-220.

IAWA Committee, 1989. IAWA list of microscopic feature for hardwood identification. International Association of Wood Anatomists, Bulletin 10: 219-332.

IBODA, 1994. Flora del Conosur. Catálogo de las plantas vasculares. http://www2.darwin.edu.ar/Proyectos/FloraArgentina/FA.asp (consulta 28 de Agosto, 2011).

InsideWood, 2004. Published on the Internet. http://www.insidewood.lib. ncsu.edu/search (consulta Septiembre, 2011).

Iriondo, M.H. 1980. El Cuaternario de Entre Ríos. Revista de la Asociación de Ciencias Naturales del Litoral 11: 125-141.

Iriondo, M.H. y Kröhling, D. 2001. A neoformed Kaolinitic mineral in the Upper Pleistocene of NE Argentina. International Clay Conference 12 (Bahía Blanca), Abstract, 6 p.

Iriondo, M.H. y Kröhling, D. 2007. La Formación El Palmar (informalmente Fm Salto Chico) y el acuífero San Salvador. Entre Ríos. $5^{\circ}$ Congreso Argentino de Hidrogeologia (Paraná), Resúmenes, p. 433-441.

Iriondo, M.H. y Kröhling, D. 2008. Cambios ambientales en la cuenca del Uruguay (desde el Presente hasta dos millones de años atrás). Colección Ciencia y Técnica, Universidad Nacional del Litoral, Santa Fe, 360 p.

Kribs, D.A. 1935. Salient lines of structural specialization in the wood rays of dicotyledons. Botanical Gazette 96: 547-557.

Kröhling, D.M. 2009. La Formación El Palmar, una unidad fluvial asignable al subestadio cálido EIO 5a (Pleistoceno Tardío) de la cuenca del río Uruguay. Natura Neotropicalis 40: 61-86.

Leisman, G.A. 1985. A fossil Lauracean (Cryptocarya) wood from the Tertiary of eastern Victoria, Australia. American Journal Botany 72: 888-896.

León, W. 2000. Anatomía del leño de 17 especies del género Ocotea Aublet. Pittieria 29/30: 53-65.

León, W. y Espinoza De Pernía, N. 2000. Estudios anatómicos del leño de siete especies del género Beilschmiedia Nees (Lauraceae). Revista Forestal Venezolana 44: 47-36.

Lutz, A.I. 1979. Maderas de angiospermas (Anacardiaceae y Leguminosae) del Plioceno de la provincia de Entre Ríos, Argentina. Facena 3: 39-63.

Lutz, A.I. 1980. Palmoxylon concordiensis n. sp. del Plioceno de la Provincia de Entre Ríos, República Argentina. $2^{\circ}$ Congreso Argentino de Paleontología y Bioestratigrafia y $1^{\circ}$ Congreso latinoamericano de Paleontología (Buenos Aires), Actas 3: 129-140.
Lutz, A.I. 1984. Palmoxylon yuqueriense n. sp. del Plioceno de la Provincia de Entre Ríos, Argentina. $3^{\circ}$ Congreso Argentino de Paleontología y Bioestratigrafia (Corrientes), Actas, p. 197-207.

Lutz, A.I. 1986. Descripción morfo-anatómica del estípite de Palmoxylon concordiense Lutz del Plioceno de la Provincia de Entre Ríos, Argentina. Facena 6: 17-32.

Lutz, A.I. 1987. Estudio anatómico de maderas terciarias del Valle de Santa María (Catamarca-Tucumán), Argentina. Facena 7: 125-143.

McKey, D. 1994. Legumes and nitrogen: the evolutionary ecology of a nitrogen demanding life style. En: J.I. Sprent y D. McKey (Eds.), Advances in Legume Systematic 5, The Nitrogen Factor. The Royal Botanic Gardens, Kew, p. 211-228.

Mädel-Angeliewa, E. y Müller-Stoll, W.R. 1973. Kritische Studien über fossile Combretaceen-Hölzer: über Hölzer von Typus Terminalioxylon G. Schönfeld mit einer Revision der bisher zu Evodioxylon Chiarugi gestellten Arten. Palaeontographica Abteilung B 142: 117-136.

Metcalfe, C.R. y Chalk, L. 1950a. Anatomy of the Dicotyledons, Volume 1. Clarendon, Oxford, $724 \mathrm{p}$.

Metcalfe, C.R. y Chalk, L. 1950b. Anatomy of the Dicotyledons, Volume 2. Clarendon, Oxford, 776 p.

Mirioni, H. 1965. Étude anatomique de quelques bois Tertiares de Colombie. Boletin de Geologia, Universidad Industrial de Santander 20: 27-59.

Mussa, D. 1958. Dicotiledôneo fóssil da formação Barreiras, Estado de Sergipe. Departamento Nacional da Produção Mineral, Divisão de Geologia e Mineralogia, Boletim 181: 1-23.

Nishida, S. 1999. Revision of Beilschmiedia (Lauraceae) in the Neotropics. Annals of the Missouri Botanical Garden 86: 657-701.

Owen, R. 1839. Fossil Mammalia. En: C. Darwin (Ed.), Zoology of the Voyage of H. M. S. Beagle, volume 2. Smith, Elther, and Co., Londres, p. 41-64.

Patel, R. 1987. Wood anatomy of the dicotyledons indigenous to New Zealand 16. Lauraceae. New Zealand Journal of Botany 25: 477-488.

Parra, J. 2009. Anatomía del leño e identificación de siete especies de Laurales en San Eusebio (Mérida, Venezuela). Pittieria 33: 59-77.

Patterer, N.I. y Brea, M. 2011. Phytolith analysis in fluvial sediments of El Palmar Formation (late Pleistocene) in eastern Argentina. $8^{\text {th }}$ International Meeting on Phytolith Research (Colorado), Abstracts, p. 42-43.

Pons, D. y De Franceschi, D. 2007. Neogene woods from western Peruvian Amazon and palaeoenvironmental interpretation. Bulletin of Geosciences 82: 343-354.

Prakash, U. y Awasthi, N. 1969. Fossil woods from the Tertiary of eastern India, II. The Palaeobotanist 30: 30-59.

Ritcher, H.G. 1981. Wood and bark anatomy of Lauraceae. Aniba Aublet. IAWA Bulletin n.s. 2: 79-87.

Richter, H.G.1987. Mature secondary xylem. En: C.R. Metcalfe (Ed.), Anatomy of the Dicotyledons, Volume 3, Magnoliales, Illiciales and Laurales, Second Edition. Clarendon Press, Oxford, p. 162-168.

Richter, H.G. y Dallwitz, M.J. 2000 onwards. Commercial timbers: descriptions, illustrations, identification, and information retrieval.

Rohwer, J.G. 1993. Nectandra. Flora Neotropica 60: 1-333.

Santos-Filho, F., Bezerra de Almeida, E., de Melo Bezerra, L., Ferreira Lima, L. y Zickel, C. 2011. Magnoliophyta, restinga vegetation, state of Ceará, Brazil. Check List. Journal of species lists and distribution 7: 478-485.

Schönfeld, G. 1947. Hölzer aus den Tertiär von Kolumbien. Abhandlungen der Senckenbergischen Naturforschenden. Gesellschaft 474: 1-53.

Suguio, K. y Mussa, D. 1978. Madeiras fósseis dos aluviōes antigos do Rio Tietê, São Paulo. Boletim IG. Instituto de Geociências da Universidade de San Pablo 9: 25-45.

The Plant List. 2010. Version 1. http://www.theplantlist.org/ (consulta Septiembre, 2011).

Tonni, E.P. 1987. Stegomastodon platensis y la antigüedad de la Formación 
El Palmar, en el Departamento Colón, Entre Ríos. Ameghiniana 24: 323-324.

Tortorelli, L.A. 1956. Maderas y Bosques argentinos. Editorial Acme, Buenos Aires, 910 p.

Tressens, S.G. 1997. El género Cryptocarya (Lauraceae) en Argentina. Bonplandia 9: 209-212.

Unger, F. 1842. Synopsis lignorum fossilium plantarum acramphibryarum. En: S. Endlicher (Ed.), Genera Plantarum. Secundum Ordines Naturales Disposita. (Suppl. II), Appendix, Wien, p. 100-102.

Unger, F. 1845. Synopsis plantarum fossilium. Leipzig. 330 p.

Van Vliet, G. y Baas, P. 1984. Wood anatomy and classification of the Myrtales. Annals of the Missouri Botanical Garden 71: 783-800.

Veroslavsky, G. y Montańo, J. 2004. Sedimentología y estratigrafía de la Formación Salto (Pleistoceno). En: G. Veroslavsky, M. Ubilla y S. Martínez (Eds.), DIRAC-FC, Montevideo, p. 147-166.

Wheeler, E.A. y Baas, P. 1992. Fossil wood of the Leguminosae: a case study in xylem evolution and ecological anatomy. En: P.S. Herendeen y D.L. Dilcher (Eds.), Advances in Legume Systematics 4: 281-301.

Wheeler, E.F. y Manchester, S.R. 2002. Woods of the Eocene Nut Beds flora. Clarno Formation, Oregon, USA. IAWA Journal, Supplement 3: $1-188$.
Wheeler, E.F., Lee, M. y Matten, L.C. 1987. Dicotyledonous woods from the Upper Cretaceous of southern Illinois. Botanical Journal of the Linnean Society 95: 77-100.

Wheeler, E.A., Wiemann, M. y Fleagle, G. 2007. Woods from the Miocene Bakate Formation, Ethiopia. Anatomical characteristics, estimates of original specific gravity and ecological inferences. Review of Palaeobotany and Palynology 146: 193-200.

Zucol, A., Brea, M. y Scopel, A. 2005. First record of fossil wood and phytolith assemblages of the Late Pleistocene in El Palmar Nacional Park (Argentina). Journal of South American Earth Sciences 20: 33-43.

Zuloaga, F.O., Morrone, O. y Rodríguez, D. 1999. Análisis de la biodiversidad en plantas vasculares de la Argentina. Kurtziana 27: 17-167.

doi: 10.5710/AMGH.17.5.2012.561

Recibido: 2 de diciembre de 2011

Aceptado: 17 de mayo de 2012 